\title{
Practical guidelines and recent advances in the Itrax XRF core-scanning procedure
}

Itrax operators

(all co-authors contributed equally)

${ }^{1}$ Menno Bloemsma

${ }^{2}$ Ian Croudace

${ }^{3,4}$ J. Stephen Daly

${ }^{5}$ Robin J. Edwards

${ }^{6}$ Pierre Francus

${ }^{7}$ Jennifer M. Galloway

${ }^{8}$ Braden R.B. Gregory

${ }^{9}$ Jyh-Jaan Steven Huang

10, 11 Anna F. Jones

${ }^{12}$ Malin Kylander

13*Ludvig Löwemark

${ }^{14}$ Yangbing Luo

${ }^{15}$ Suzanne Maclachlan

${ }^{16}$ Christian Ohlendorf

${ }^{8}$ R. Timothy Patterson

${ }^{17}$ Christof Pearce

16, 18Jörn Profe

${ }^{19}$ Eduard G. Reinhardt

${ }^{12}$ Christian Stranne

${ }^{20}$ Rik Tjallingii

11,3 Jonathan N. Turner

${ }^{1}$ Advanced Sediment and Core Analysis Research (ASCAR), Minister van Houtenlaan 5, 1981 EA Velsen-Zuid 
${ }^{2}$ GAU-Radioanalytical, University of Southampton, National Oceanography Centre, Southampton, SO14 3ZH

${ }^{3}$ UCD Earth Institute, University College Dublin, Belfield, Dublin 4, Ireland

${ }^{4}$ School of Earth Sciences, University College Dublin, Belfield, Dublin 4, Ireland

${ }^{5}$ School of Natural Sciences, Trinity College Dublin 2, Ireland

${ }^{6}$ Centre Eau Terre Environnement, Institut National de la Recherche Scientifique, Québec, G1K 9A9, Canada, and Canada Research Chair in Environmental sedimentology

${ }^{7}$ Natural Resources Canada/Ressources naturelles Canada Geological Survey of Canada/Commission géologique du Canada, 3303 33rd Street N.W., Calgary, AB, Canada, T2L $2 \mathrm{~A} 7$

${ }^{8}$ Ottawa-Carleton Geoscience Centre and Department of Earth Sciences, Carleton University, 1125 Colonel By Drive, Ottawa, ON, K1S5B6, Canada

${ }^{9}$ Institute of Geology, University of Innsbruck, Innrain 52, A-6020 Innsbruck, Austria ${ }^{10}$ Department of Geography, Edge Hill University, St Helens Road, Ormskirk, Lancashire L39 4QP

${ }^{11}$ School of Geography, University College Dublin, Belfield, Dublin 4, Ireland

${ }^{12}$ Department of Geological Sciences and the Bolin Centre for Climate Research, Stockholm University, 10691 Stockholm, Sweden

${ }^{13}$ Department of Geosciences, National Taiwan University, No 1. Sec. 4 Roosevelt Road, P.O. Box 13-318, 106 Taipei, Taiwan

${ }^{14}$ MLR Key Laboratory of Saline Lake Resources and Environments, Institute of Mineral Resources, CAGS, Beijing 100037, China

${ }^{15}$ BOSCORF, University of Southampton, National Oceanography Centre Southampton, SO14 3ZH, UK

${ }^{16}$ University of Bremen, Geopolar, Celsiusstr. 2, 28359 Bremen, Germany

${ }^{17}$ Department of Geoscience, Arctic Research Centre and iClimate, Aarhus University, Høegh-Guldbergs Gade 2, 8000 Aarhus C, Denmark

${ }^{18}$ Justus Liebig University Gießen, Department of Geography, Section Geoinformatics and Remote Sensing, Senckenbergstr. 1, 35390 Gießen

${ }^{19}$ School of Geography and Earth Sciences, McMaster University, 1180 Main St. W, Hamilton, ON, L8S 4L8, Canada

${ }^{20}$ Section 5.2 Climate Dynamics and Landscape Evolution, GFZ German Research Centre for Geosciences, Telegrafenberg, 14473 Potsdam, Germany 
*Corresponding author: loewemark@gmail.com 


\section{ABSTRACT}

XRF core scanning has evolved to become a standard analytical technique for the rapid assessment of elemental, density and textural variations in a wide range of sediments and other materials, with applications ranging from palaeoceanography, paleoclimatology, geology, and environmental forensics to environmental protection. In general, scanning provides rapid, non-destructive acquisition of elemental and textural variations at sub-millimetre resolution for a wide range of materials. Numerous procedural adaptations have been developed for the growing number of applications, such as analyses of unconsolidated, water-rich sediments, powdered soil samples, or resin bags. Here, practical expertise and guidance from the Itrax community, gained over 15 years, is presented that should provide insights for new and experienced users.

Keywords: XRF Core Scanning; Itrax; X-ray fluorescence; X-ray radiography; geochemistry

\section{Introduction}

After the initial experimental proving phase of XRF core scanning, which started more than two decades ago, this analytical method has now developed well beyond its pioneering phase to become an indispensable standard technique in many fields (Croudace, 2003; Croudace et al., 2006; Croudace and Rothwell, 2015b; Haschke, 2006; Jansen et al., 1998; Richter et al., 2006; Rothwell and Croudace, 2015; Weltje et al., 2015; Weltje and Tjallingii, 2008). During the XRF Core Scanning 2017 international meeting at the National Taiwan University in Taipei, Taiwan, which for the first time brought together representatives and users from all the main XRF core scanner brands, a large number of interesting new applications using the XRF core scanning technique were presented. Based on the progress made over the last decade or so, a review summarizing the different operating protocols that have been developed for the Itrax XRF Core Scanner (Cox Analytical Systems, Gothenburg, Sweden) is timely. The Itrax XRF core scanning procedure may be subdivided into a number of steps: (1) instrumental checks to ensure that the machine is operating properly, (2) sample preparation, (3) choice of sample holders for core or discrete samples, (4) surface scan to ensure samples are level and to make any adjustments for problematic samples, (5) X-ray radiography, (6) choice of optimal XRF scanning parameters such as exposure time, step size and X-ray tube settings, (7) post-analysis processing of data, and (8) efficient data visualization. For many of these steps, various practical solutions developed by Itrax operators worldwide are presented 
for the benefit of other users. We break the coring process down into its different components and illustrate the various approaches that have been developed to improve or facilitate the processing of different kinds of samples and materials. The structure of this article therefore follows the workflow of analysing samples using the Itrax XRF Core Scanner.

\section{Pre-analysis considerations}

\subsection{Instrumental checks}

The stability of an instrument influences its analytical performance and regular checks can assure that an individual instrument is performing correctly. It is advisable to perform the checks on a weekly or monthly basis and always following a tube change. A written record of each check-up is kept so that changes in the instrument can be assessed. While this procedure should be tailored for each instrument, a basic version is described here (Table 1).

Table 1. Instrumental checks to be performed on a regular basis.

\begin{tabular}{|c|c|}
\hline Component & Description \\
\hline $\begin{array}{l}\text { 1. Cooling } \\
\text { system }\end{array}$ & $\begin{array}{l}\text { Record the cooling water flow rate and the chiller temperature. } \\
\text { The latter should be around } 20^{\circ} \mathrm{C} \text { depending on the cooling } \\
\text { system. If you have a filter, note its status and any need for } \\
\text { change. }\end{array}$ \\
\hline $\begin{array}{l}\text { 2. Safety } \\
\text { interlocks }\end{array}$ & $\begin{array}{l}\text { Using the HV panel or the software set the voltage and current to } \\
10 \mathrm{kV} \text { and } 5 \mathrm{~mA} \text {. Open the shutter by pressing F4 on the HV unit } \\
\text { or using the drop down option under Operate. Check each of the } \\
\text { three lids in turn re-opening the shutter for each }\end{array}$ \\
\hline 3. Surface scan & $\begin{array}{l}\text { Make a surface scan of the acrylic-block. Check that the } \\
\text { illumination tubes are working properly and compare the } \\
\text { measurement scales on the Core Scanner Panel with those on the } \\
\text { acrylic-block. You should see the step wise pattern of the Al } \\
\text { staircase in your surface scan height data. }\end{array}$ \\
\hline 4. Optical image & $\begin{array}{l}\text { Save the optical image under File }>\text { Save optical image using a } \\
\text { designated folder and the convention Optical Image-Year-Month- } \\
\text { Day. }\end{array}$ \\
\hline $\begin{array}{l}\text { 5. Radiation } \\
\text { protection }\end{array}$ & $\begin{array}{l}\text { Check the radiation by setting the acrylic-block so that the } \mathrm{Al} \\
\text { portion is under the beam. Set the voltage to } 60 \mathrm{kV} \text { creating the } \\
\text { most X-ray scatter and generating the 'worst case scenario'. }\end{array}$ \\
\hline
\end{tabular}




\begin{tabular}{|c|c|}
\hline & $\begin{array}{l}\text { Using the dose meter check for radiation along the seams of the } \\
\text { main tower and wings. Note the counts per second. This should } \\
\text { be low ( }<2 \mathrm{cps}) \text {. }\end{array}$ \\
\hline $\begin{array}{l}\text { 6. Line camera } \\
\text { signal }\end{array}$ & $\begin{array}{l}\text { Move the acrylic-block home and set the radiographic parameters } \\
\text { to a standard setting that you use consistently for each check-up } \\
\text { (e.g., } 40 \mathrm{kV}, 20 \mathrm{~mA} \text { and } 25 \mathrm{msec} \text { ). Exit the Set Radiographic } \\
\text { Parameters and using Window> Show Line Camera Signal. The } \\
\text { signal will appear in black. Load the last reference signal } \\
\text { (Reference Files > Load Reference), which should be the red line } \\
\text { on the Radiographic Signal panel. The black and red lines should } \\
\text { overlap. If there is more than a } 10 \% \text { difference, change the } \\
\text { alignment of the optics. This is done using the right hand knobs } \\
\text { on the front of the machine (be sure to retract the XRF detector } \\
\text { before doing so). Note the value for the black line and then Clear } \\
\text { the Ref Signal. Press Reference File > Save Ref Signal and save } \\
\text { it as a dated file (Tube-Year-Month-Day) in a designated folder. }\end{array}$ \\
\hline $\begin{array}{l}\text { 7. XRF } \\
\text { performance }\end{array}$ & $\begin{array}{l}\text { Move the block to where the reference glass sits. Press Set XRF } \\
\text { Parameters. Re-enter lab specific standard settings (e.g., } 30 \mathrm{kV} \text {, } \\
35 \mathrm{~mA} \text { and } 100 \mathrm{sec} \text { ) and let the analysis run for the designated } \\
\text { time and apply a pre-established settings file for the reference } \\
\text { glass. Note the ICR, OCR, MSE and peak area of the most } \\
\text { common elements (e.g., Si, K, Ca, As, Zr and coh peak). These } \\
\text { should be roughly the same as the previous check-up. Note with a } \\
+ \text { or - sign whether value have gone up or down. Save the spectra } \\
\text { under File > Save Spectra. When ready with this open the latest } \\
\text { background spectra found under File> Open Background Spectra. } \\
\text { There should be good overlap between the pink (background } \\
\text { spectra) and the newly measured spectra (black). Note if these } \\
\text { differ significantly. }\end{array}$ \\
\hline 8. Documentation & $\begin{array}{l}\text { Set up separate folders to save the optical images, radiographic } \\
\text { signals and XRF glass spectra. Also copy the XRF data and insert } \\
\text { the optical image in a designated file (e.g., ppt) recording the tube } \\
\text { used and the date for each check-up file. }\end{array}$ \\
\hline
\end{tabular}


By collecting the above information over a longer time period it is possible to better diagnose and solve problems when they do occur since individual users will know what is normal for their instrument.

\subsection{Sample preparation and surface scan}

Although XRF core scanning in itself is non-destructive, sample preparation may damage the material or possibly render it unusable for subsequent analysis. In the Itrax system (a contactless/stand-off instrument), the X-ray tube remains fixed and the sample is moved beneath the detector. This design differs from most competing instruments that use low power. The Itrax X-ray tube is a high voltage unit that is physically quite large and requires an HV cable attachment and water cooling. While the detector can move up and down to some extent to accommodate for variations in the microtopography of the sample surface, a smooth and even surface is essential for reliable results. A bubble level is a useful tool to ensure/verify that samples are essentially horizontal/parallel to the sample holder. If they are not level over the scan length then users should make adjustments by judicious packing with low density materials such as folded paper or Clingfilm. Sample surfaces that are not flat can be improved by scraping the core with a broad spatula (perpendicular to the long core axis to avoid cross-contamination and damage to core textures). This is also often required when cores have been stored and oxidized/saline layers have formed. In cores with high organic content, cores that have remained in storage for an extended period, or other samples, such as hard rock cores or cave carbonates, cracks, holes, or breaks in the sample surface may cause a variety of problems. Because measurements are recorded continuously as the core moves below the detector and are stored as data at the mid-points of each step, cracks and other disturbances cannot be avoided by choosing a step size that omits individual cracks and gaps. Furthermore, larger cracks and gaps may cause the detector to move away from the sample surface as these are treated as "no go" zones in order to prevent damage to the XRF detector. This lifting and lowering of the XRF detector over intervals with cracks may result in the loss of data. One way to circumvent this is to apply a thin, removable PTFE (polytetrafluoroethylene thread seal tape) tape along the scan path of the laser distance meter during the initial surface scan to simulate a smooth surface. After completion of the topographical scan the tape is removed, and the detector will pass over the cracks during XRF scanning without any adjustment in height (Figure 1). The cracks can often be easily identified by abrupt increases in Ar, an element that is abundant in the air in the cracks, and 
removed from the dataset without influencing nearby regions. Operators should remain alert to possible Ar peaks indicative of core-surface degradation. Cores with thin, organic-rich, or laminated sediment may have been observed to dry out so fast during analysis that cracks not visible during preparation or pre-scan have formed during the scanning process. The use of a XRF film (e.g. Mylar or polypropylene) helps to reduce drying but the user needs to ensure that an X-ray absorbing surface water layer does not form as this will influence the XRF scanning data.

A loss of data similar to that caused by core surface cracking can occur at the end of a core section because of the abrupt drop in the surface topography. The drop must be avoided by the XRF detector in order to protect the detector from damage. The raising of the detector means that the last several $\mathrm{mm}$ of core analysed may be biased by a larger distance between the detector and sample's surface. This can easily be circumvented by placing a piece of "dummy core" level with the core surface at the end of the sample (Figure 1A and 1B, a white tape was placed in the end of the core to the left). Phenolic foam (Floral Foam) is of practical use as it is easily detected by XRF due to its low density, and can be easily sliced to accommodate most sample holders and sample shapes.

In some cores where the sample surface has subsided due to sediment flow or compaction, the sediment may have to be elevated to measuring distance of the detector by inserting planar or wedge-shaped objects below the sediment. In the case of lacustrine cores retrieved by Russian Corer, the sample material is often considerably smaller than the PVC-liner in which it is stored. Here the sample can be flipped onto an acrylic glass board so that the curved, outer side is measured. In this way the detector will not be hindered by the protruding edges of the liners (Figure 2).

An alternative method, somewhat similar to the method described above for the Russian Corer, has been used to scan whole-round lake sediment cores collected using a Geo Core (Columbus, Ohio) corer. The procedure involves carefully extruding the sediment from the aluminium core tube onto industrial-grade cling film. The best and largely flattest part along the core length is covered with a length of $2 \mu \mathrm{m}$ XRF film. The whole sediment core is then gently rolled onto the cling-film to form a sausage-shape. This can be rolled onto structureless MDF board for safe storage. When the core is ready to be run on the Itrax the Cling-film is carefully peeled back to reveal the $2 \mu \mathrm{m}$ XRF film (Figure 2). The core 'sausage' is then adjusted on a flat board so the XRF film is uppermost. The board, with its 
level core surface (analogous to surface in Fig 2.B) can be loaded onto the Itrax sample holder ready for scanning.

\subsection{Types of sample holders}

During scanning, the core sections are placed onto a tray that incrementally moves cores past the measuring unit in the central chamber of the XRF Core Scanner. The tray has adjustable rails that allow the sample height to be adjusted, and the tray may also be shifted to the left or right to avoid problematic sections or intervals that have been sampled for other analysis. A special adapter is also available to accommodate the scanning of U-channels used for paleomagnetic studies. However, for non-standard samples innovative solutions may be necessary. Below, approaches to measure still frozen freeze-core samples, powdered samples, and resin samples are described.

\subsubsection{Freeze core vessel}

Sediment near the surface-water interface in many lacustrine environments consists of a poorly consolidated colloidal soup that is difficult to sample using conventional coring techniques without causing homogenization of the geochemical record. This is of particular importance in environments with low sedimentation rate where the upper few centimetres can represent centuries of deposition (e.g. the Canadian Arctic, Crann et al., 2015). Furthermore, this poorly consolidated material is not cohesive enough for XRF core scanning. Freeze coring freezes sediments in situ to the coring device and preserves the stratigraphy of the sediment-water interface. Here we describe the construction of a novel sample holder capable of maintaining freeze core integrity for more than two hours and methods for analysing the freeze cores.

An Ice Box Freeze Core holder (iBox-FC) was created to ensure short slabs of freeze cores remain frozen during analysis. The iBox-FC consists of an open-topped box constructed from 3-cm-thick Styrofoam that is divided into 9 chambers using high density polyethylene (HDPE) and filled with freeze pack gel (e.g. hydroxyethyl cellulose (Cellusize), sodium polyacrylate, or vinyl-coated silica gel); the central chamber is only partially filled to accommodate freeze core material (see Figure 3 and Gregory et al., (this issue) for detailed dimensions). Short slabs $(\sim 12.5 \mathrm{~cm})$ of frozen sediment slotted into the central chamber of the iBox-FC show minimal melting $(<1 \mathrm{~mm})$ after 2 hours of analysis. As water can damage the Itrax XRF Core Scanner, all joints of the iBox-FC should be sealed with silicone gel, and the outer chambers of the iBox-FC covered with an HDPE lid during analysis (Figure 3C). To 
facilitate easy removal of freeze core material, and to minimize contamination risk, it is recommended that freeze core sections be placed in a separate container sized to fit within the central chamber of the iBox-FC. The design presented here uses polypropylene boxes (US Plastics Corp. 20 dram Flextop box, product \#201214; $13.4 \mathrm{~cm}$ long, $4.1 \mathrm{~cm}$ wide and $1.8 \mathrm{~cm}$ deep.

Freeze cores must be sub-sectioned longitudinally and latitudinally to fit inside the iBox-FC. Following initial cleaning, freeze cores are sectioned into small slabs using a hacksaw and a ripsaw. Hacksaws should be used for latitudinal cuts as their thin blade minimizes material loss. A rip saw, which has much larger teeth, is more efficient for longitudinal slices, reducing time required for freeze core subsectioning. Freeze core slabs should be cleaned after they are sectioned to minimize risk of contamination from sub-sectioning instruments. During this final cleaning stage, the freeze core surface undergoing analysis should be made as smooth and level as possible. A clean microscope slide can be used to scrape the surface of the core to provide a smooth surface for analysis. If the core surface is too uneven to be levelled by removing the upper few millimetres of core surface, HDPE shims placed inside the inner box can be used to level the core. The iBox-FC must be completely frozen before freeze core slabs are added, otherwise the freeze core slab will melt before the iBox-FC freezes completely.

Once the iBox-FC is removed from the freezer and the freeze core slab inserted into the holder, a thin bi-directional PET film with a thickness of $1.4 \mu \mathrm{m}$ must be affixed to the core following typical XRF core scanning procedure. The surface of the freeze core slab must be melted slightly by exposing the core surface to a heat source to affix the PET film, as the film does not adhere well to low-moisture surfaces. After the PET is affixed to the core surface, the iBox-FC can be slotted into the Itrax XRF Core Scanner with the rails at the lowest setting (Figure 3C).

Afterwards, analysis proceeds following standard Itrax analytical procedures (Croudace et al., 2006; Gregory et al., this issue). Depending on the thickness of the freeze core slab and ambient temperature, freeze core slabs will remain cohesive for at least two hours with the Itrax XRF Core Scanner settings being adjusted to accommodate this timeline. If higher resolution or longer exposure times are desired during analysis, smaller freeze core slabs may be required. During initial testing, X-ray imaging of cores was excluded due to time 
constraints and possible interference of the signal from the iBox-FC. If X-ray imaging is desired, analysis should take place in a separate run from XRF analysis, and the freeze core returned to the freezer in between runs.

Initial testing of the iBox-FC took place at McMaster University in Hamilton, Ontario, during humid summer months. As a result of the humidity, small water droplets formed on the PET film on the surface of the freeze core. During re-analysis of the same slabs in the subsequent fall, condensation was greatly reduced. We recommend analyzing freeze cores either during less humid months or in a climate controlled room.

Once Itrax XRF Core Scanning analysis is complete, data from freeze cores must be distinguished from that of non-core material. Comparison of core images to XRF Core Scanner results using Redicore software (Cox Analytical Systems, Gothenburg, Sweden) is useful for this purpose, particularly when examining abrupt changes in major element concentrations, total counts per second, sample position, and the total length of core slabs recorded during sub-sectioning (Figure 4). Preliminary iBox-FC results show edge effects that occur through the lowermost $5 \mathrm{~mm}$ of freeze core slabs during analysis. These edge effects result in decreased elemental concentrations and increased X-ray scatter when compared with the rest of the slab (Figure 4; see Gregory et al, this issue, for additional discussion). The use of elemental log-ratios when reporting the data nearly completely mitigates these edge effects, and also minimizes subtle amplitude changes in elemental concentrations caused by minor shifts in the freeze core height relative to X-ray source between freeze core sections. It is thus recommended that elemental ratios or elemental logratios be used (e.g., Kylander et al., 2011; Gregory et al., this issue; Löwemark et al., 2011; Weltje and Tjallingii, 2008) as a matter of course for interpretation of geochemical data generated from freeze cores subsequent to analysis using the Itrax XRF Core Scanner.

\subsubsection{Scanning freeze dried sections}

Another method of dealing with unconsolidated sediments is to freeze dry the samples. This removes the water in the sediment, one of the potential matrix issues with XRF core scanning, but retains the structure of the material. This technique was developed using samples from Nylandsjön in northern Sweden, which has been monitored and sampled yearly since 1979 (Galman et al., 2008; Renberg, 1982; Rydberg, 2008). Sediment cores are kept 
frozen from the time of collection until freeze-drying. Core slabs $\sim 1 \mathrm{~cm}$ thick and $3 \mathrm{~cm}$ wide are placed on plastic trays and supported with foam to maintain the physical integrity of the sample during freeze-drying (Figure 5a). The entire tray is then placed in the Itrax and scanned using standard procedures for scanning sediment cores. In samples with horizontal varves good reproducibility between parallel scans is observed although some signal smearing is likely (Figure 5).

\subsubsection{Discrete samples and powdered samples}

The measurement of discrete powdered environmental samples with an Itrax XRF Core Scanner is a time- and cost-efficient alternative to conventional wavelength dispersive (WD)or energy dispersive (ED)-XRF analyses when quantitative data are of subordinate importance (Profe and Ohlendorf, 2018). Since the Itrax XRF Core Scanner is designed for continuous measurements of sediment cores, but not for discrete samples, a sample carrier was designed that allows the measurement of discrete powdered samples in scanning mode (Ohlendorf, 2018). One carrier holds 30 sample cups with a volume of $0.88 \mathrm{~cm}^{3}$ each. The shape and dimensions of the sample cups are adjusted to the measurement geometry of the Itrax XRF Core Scanner. A maximum of five carriers, i.e. 150 sample cups, can be measured in one run with a step size of $5 \mathrm{~mm}$ and a count time of up to $100 \mathrm{~s}$ per sample. Subsequent data processing for such a run involves deletion of every second spectrum which are biased by the acrylic glass rims of the sample cups (Ohlendorf, 2018), recalculation of a new sum spectrum containing sample spectra only, fit optimization of the new sum spectrum and batch processing of the sample spectra. This measurement protocol was applied to samples of several loess-paleosol sequences as these are usually discretely sampled and characterized by silt-sized particles which facilitates sample preparation (Profe et al., 2018a; Profe et al., 2018b; Profe et al., 2016; Zolitschka et al., 2014). All measurements yielded good data repeatability with a mean relative standard deviation of $<1.5 \%$ for main elements except for $\mathrm{Al}(14.3 \%)$ and $\mathrm{Ba}(14.9 \%)$.

Other discrete sediment sample holders have been designed for analysis of sediment samples using the Itrax XRF Core Scanner, with minimal pretreatment (unpowdered, semidry, paste consistency, samples). The carrier described here is particularly useful for costeffective determination of spatial patterns from landscape derived terrestrial, marine and lake bottom sediment samples or for analysis of severely degraded core material.

It is an easy-to-assemble, low-cost, acrylic sample carrier that holds up to 60 discrete samples designed to analyse discrete sediment samples by arranging them sequentially in 1.5 
$\mathrm{cm}^{3}(1.5 \times 1 \times 1 \mathrm{~cm})$ sample reservoirs to mimic the orientation of standard sediment cores (Figure 6). The Itrax XRF Core Scanner can accommodate two of these sample carriers at once to allow analysis of up to 120 discrete samples in one run at high resolution. The $1.5 \mathrm{~cm}$ surface length scanned by each sample carrier provides multiple measurements of the same discrete sample to provide an understanding of the XRF Core Scanner precision for each sample as well as a determination of sample heterogeneity. Sediment samples are prepared for analysis by centrifuging ( 4 minutes at $4000 \mathrm{rpm}$ minimum recommended), decanting the supernatant, and then drying samples at room temperature until they reach the consistency of paste. Sediment samples can then be loaded into the sample carrier and analysed following standard Itrax XRF Core Scanner procedures. A simple brass cover (Figure 6C), which isolates previous and subsequently loaded sample cups, prevents cross contamination, and facilitates rapid loading of the sample carrier. For analysis, the sample carrier is placed on the Itrax-XRF Core Scanner rails at the highest setting. Post-analysis data processing must be undertaken to remove the acrylic borders from the dataset. These borders can be easily identified and removed based on abrupt decreases in the ratio of incoherent/coherent X-ray scatter and abundant elements (Fe and $\mathrm{Ca}$ are typically useful), as well as a sharp increase in the total counts per second (Gregory et al., 2017).

\subsubsection{Ion exchange resin samples}

Sample cups used for powdered material can also be applied to pollution monitoring studies. As a passive sampling sorbent, ion exchange resins take up many cations relevant for environmental studies and can be immersed in natural waters for a fixed period of time for monitoring purposes (e.g., Van Grieken, 1982). The rapid uptake rate and low cost of resins provide a simple method to record pollutants and allow for a high sampling density, but it can also be difficult to digest such amounts of samples with conventional chemical extraction and analysis procedures. Therefore, the Itrax-XRF core scanner has been introduced to analyse element concentrations in resins. Unlike sediment samples, which usually have high heterogeneity due to the variability of physical properties and sample matrix, the dry and homogenized resins can minimize interference, making them ideal samples for XRF scanning.

The resin samples can be placed into the sample cups described above, and covered with a $1.4 \mu \mathrm{m}$ thin Mylar X-Ray Film to prevent contamination and disturbance by static electricity, and then scanned with the Itrax XRF Core Scanner. With 100 seconds exposure time, the correlation coefficients between scanning intensities and reference concentrations of 
laboratory-prepared reference resins are all higher than 0.97 for pollution related elements such as $\mathrm{Cr}, \mathrm{Mn}, \mathrm{Ni}, \mathrm{Cu}, \mathrm{Zn}$, and $\mathrm{Pb}$. Moreover, as suggested by Huang et al. (2016) from the experience of sediment reference standards, the strong linear relationship between scanning intensities and reference concentrations of resins remains similar even with exposure time as brief as 1 second. Thus, this method provides a fast and inexpensive method to quantitatively assess multiple element concentrations in the resins, and can be used as an environmental monitoring tool for large geographic areas in order to understand the variations of environmental contaminants across a landscape.

\subsection{Considerations for special sediments/substrates}

Lithified sediment and rock samples can be successfully scanned with the Itrax XRF Core Scanner, although XRF core scanner operators must be cautious of possible issues arising from the crystalline nature of some rock samples. For example, Miocene sandstones from outcrops in NE Taiwan containing numerous diagenetically altered trace fossils (Löwemark et al., 2016) were scanned using the Itrax XRF Core Scanner. Mineralogical thin section analysis of these trace fossils is time consuming and cumbersome. Alternatively, using the Itrax XRF Core Scanner, and aligning structures of interest perpendicular to the scanning direction, interesting results were obtained. Using this method, a scan comparing the elemental composition of the trace fossil Ophiomorpha to surrounding sediment revealed significant enrichment of $\mathrm{Fe}$ and $\mathrm{Ca}$ in the walls of the tubes, explaining their greater resistance to erosion (Figure 7).

It is also possible to analyse rock samples. Skelton et al. (2010) used XRF Core Scanning to examine freshly cut, flat, unpolished rock cross section in order to characterize chemical mobility related to the segregation of epidote. The resulting XRF spectra were inspected for possible diffraction lines that could have been caused by the crystalline nature of the material subject to analysis. However, diffraction lines were found to be minimal and a clear change in major elements ( $\mathrm{Al}, \mathrm{Si}, \mathrm{Ca}$ and $\mathrm{Fe}$ ) was observed across the margin of epidote segregations, providing invaluable insight into mobility of these elements (Skelton et al., 2010).

The measurement of Ca-rich samples such as speleothems can cause considerable analytical challenges due to the formation of Ca sum peaks that can distort element signals. In the case of a speleothem-based flood history, however, Finné et al. (2015), were able to easily identify the intervening mineral-rich layers using XRF Core Scanning. This provided information 
comparable to conventional thin section analyses more commonly used to develop speleothem-based flood history (Finné et al., 2015).

\section{Analysis of sample}

\subsection{X-ray radiography}

\subsubsection{A radiograph standard}

When scanning a large batch of core sections from a long sediment section, the radiography settings might not be similar from one section to another. Indeed, sediment density or composition may change with depth (e.g. compaction, lithological changes) and the operator needs to adjust radiographic settings in order to maintain a good radiography quality. Performing a scan of the acrylic-block for every run is not practical because of its relatively large size (26 cm of scanning space). An alternative to the acrylic-block is a more compact version of the aluminium staircase included in the acrylic-block (Francus et al., 2015), that is only $2 \mathrm{~cm}$ thick and can be placed at the beginning or the end of each sample or core section, hence minimizing the amount of additional time needed to include a radiographic reference in each run. This radiographic reference sample allows for optimizing the voltage, current and dwell time independently for each run, and, during the post-analysis step, to bring all sections on a common X-ray attenuation scale using a simple image analysis protocol (Francus et al., 2015). Furthermore, monitoring of this radiographic reference sample can be used to identify drift of the X-ray tube and aging of detector and is indispensable for inter-laboratory comparison purposes.

\subsubsection{Combining overlapping images}

While optical images taken by an Itrax Core Scanner typically cover the entire width of a core sample, radiographic images are limited to a width of $17.6 \mathrm{~mm}$ by the size of the X-ray tube. This results in a narrow radiographic image along the centre-line of the core section, covering only a small fraction of a typical core sample. To increase this limited coverage, it is possible to run repeated scans along different offsets from the sample centre. Besides the standard centre position, the core sample holder can be manually adjusted to 1 or $2 \mathrm{~cm}$ in either direction perpendicular to the movement of the sample in the scanner. Several radiograph-only scans can be performed in just a few hours. A maximum of 5 images (centerscan +1 and $2 \mathrm{~cm}$ offsets to each side) can then be combined with image-processing software 
such as Adobe Photoshop to create a composite image of up to $57.6 \mathrm{~mm}$ total width. Figure 8 shows an example of a composite image produced from 3 overlapping scans.

Sediment cores are typically cylindrical which results in thinning of the sediment package when moving outwards from the centre-line. This is also visible in Figure 8, where the image appears lighter further away from the centre along the y-axis. Operators can compensate for this by applying a graduated brightness filter in Adobe Photoshop.

\subsubsection{Post-processing of RAW files}

The radiographic images produced by the Itrax XRF core scanner are composed of individual line scans, with $188 \mu \mathrm{m}$ spacing in the direction of core movement. This results in a resolution of approximately 5 pixels $/ \mathrm{mm}$ in the final radiographic image. The individual line scans however, contains 891 pixels in the $17.6 \mathrm{~mm}$ beam width, corresponding to approximately 50 pixels $/ \mathrm{mm}$. To compensate for this non-equal distribution of pixel density along the different axes of the dataset, the final tif image exported from the Itrax software contains 5 pixels $/ \mathrm{mm}$ in both directions. The data is thus downsampled to create squareshaped pixels. However, a radiographic scan from the Itrax XRF Core Scanner, produces not only a .tif file with the radiographic image but also a raw file that contains all the raw data. In the .raw file all the individual line scans with full resolution are preserved. Rather than downsampling in one direction, a MATLAB script was developed to upsample the other direction (Supplementary File 1). The script produces a high resolution radiographic image based on the .raw file with square-shaped pixels, by keeping the original 50 pixels $/ \mathrm{mm}$ resolution of the line scans, and interpolating the lower resolution 5 pixels $/ \mathrm{mm}$ in the $\mathrm{x}$ direction using a spline interpolation to the same resolution (Figure 9). The same script also automatically adjusts the intensity levels of the image based on the data in the raw file. This creates an image with consistent brightness and contrast adjustments which are normally done in either RediCore or Adobe Photoshop.

\subsection{XRF scanning quality and precision issues}

\subsubsection{Choosing optimal exposure time}

Minimizing the measuring time when analysing material with the Itrax XRF Core Scanner is especially advantageous when dealing with large volumes of core material. However, exposure times of XRF Core Scanners used by different researchers for different materials vary greatly (Table 2). This depend partly on the generation of the detector owned by the Itrax user since count-rate capability has increased significantly (approximately 10 times) 
since the original scanner was produced in 2003 (Croudace et al, 2006). Finding the suitable minimum exposure time for the scientifically relevant elements is essential in order to obtain reliable data efficiently. To test the minimum acceptable exposure times for different elements, silt- and clay-rich lake sediment (TOC: 1.7-4.2 \%), samples where repeatedly analysed with decreasing exposure times ranging from 100 to 3 seconds $(100,80,60,50,40$, $30,25,20,15,10,8,7,6,5,4$ and 3 seconds) and different voltages and currents $(30 \mathrm{kV}, 30$ $\mathrm{mA} ; 30 \mathrm{kV}, 55 \mathrm{~mA} ; 40 \mathrm{kV}, 30 \mathrm{~mA}$ ) using a Mo X-ray tube. Acceptable minimum exposure times should meet the following three conditions: (1) the peak area of high-sensitivity elements $(\mathrm{S}$ to $\mathrm{Pb})$ must surpass between 0.0001 and $0.5 \%$ of the total peak area and the peak areas of low-sensitivity elements ( $\mathrm{Al}$ and $\mathrm{Si}$ ) must be $<5 \%$ of the total peak area to be considered accurate (Marshall et al., 2012); (2) For a given scan time, there is no zero value for the peak area; and (3) down-core trends in elemental peak areas throughout a given core section show the same trend between the suitable minimum exposure time and 100 seconds.

The results show that for most elements, an exposure time of 7 seconds (using a silicon-drift, $7 \mathrm{~mm}^{2}$, "reset" model, low volume detector) is sufficient to obtain reliable results for this lake core (Figure 10). Aluminium and $\mathrm{Si}$, however, required longer exposure times to meet the aforementioned criteria than was required for other elements. Increasing the current $(\mathrm{mA})$ allows reduction in the exposure time required to meet minimum precision requirements, although increasing the voltage does not have a substantial influence on minimum possible exposure times.

Table 2. Variations in exposure times used for different sample types scanned with the Mo X-ray tube on the Itrax XRF scanner.

\begin{tabular}{|l|l|l|l|}
\hline Sediment Core Type & Exposure time & Voltage and current & Reference \\
\hline $\begin{array}{l}\text { Lake Bramant (fine detrital clays, } \\
\text { TOC: 0-4\%) }\end{array}$ & $10 \mathrm{~s}$ & & (Guyard et al., 2007) \\
\hline $\begin{array}{l}\text { A variety of sediments: sandstone } \\
\text { reservoir rock; muddy marine } \\
\text { sediment with low carbonate }\end{array}$ & $100 \mathrm{~s}$ & $30 \mathrm{kV}, 30 \mathrm{~mA}$ & (Croudace et al., 2006) \\
$\begin{array}{l}\text { content, petroleum and carbonate- } \\
\text { rich shale laminated }\end{array}$ & & $30 \mathrm{kV}, 45 \mathrm{~mA}$ & (Lintern et al., 2016) \\
\hline $\begin{array}{l}\text { Yarra River sediment core (clay lake } \\
\text { sediment core) }\end{array}$ & $10 \mathrm{~s}$ & & \\
\hline
\end{tabular}




\begin{tabular}{|l|l|l|l|}
\hline $\begin{array}{l}\text { Suigetsu lake sediment core (clay lake } \\
\text { sediment) }\end{array}$ & $20,10,6,5,4 \mathrm{~s}$ & $\begin{array}{l}60,50,40,30 \mathrm{kV} \text {, and } \\
40,30 \mathrm{~mA}\end{array}$ & (Marshall et al., 2012) \\
\hline $\begin{array}{l}\text { Sand and siltstones, tills and } \\
\text { meltwater deposits, total inorganic } \\
\text { carbon (TIC) = 8.33\% }\end{array}$ & $10 \mathrm{~s}$ & $30 \mathrm{kV}, 40 \mathrm{~mA}$ & (Buechi et al., 2017) \\
\hline $\begin{array}{l}\text { Marine sediment core (sand and clay, } \\
\text { TOC: 0-4.5\%) }\end{array}$ & $20 \mathrm{~s}$ & $30 \mathrm{kV}, 40-50 \mathrm{~mA}$ & (Shi et al., 2016) \\
\hline $\begin{array}{l}\text { Marine sediment core (high Corg } \\
\text { clayey sapropel units) }\end{array}$ & 35 or $45 \mathrm{~s}$ & $55 \mathrm{kV}, 50 \mathrm{~mA}$ & (Thomson et al., 2006) \\
\hline $\begin{array}{l}\text { Paddy's Lake sediment core (bulk } \\
\text { sediment rich in organic matter) }\end{array}$ & $10 \mathrm{~s}$ & $30 \mathrm{kV}, 55 \mathrm{~mA}$ & (Beck et al., 2017) \\
\hline $\begin{array}{l}\text { Marine sediment linking to volcanism } \\
\text { (silt and clay) }\end{array}$ & $10 \mathrm{~s}$ & $30 \mathrm{kV}, 40 \mathrm{~mA}$ & (Gjerløw et al., 2016) \\
\hline $\begin{array}{l}\text { Lacustrine sediments (gravel, sand } \\
\text { and silt/clay) }\end{array}$ & $5 \mathrm{or} 10 \mathrm{~s}$ & $30 \mathrm{kV}, 55 \mathrm{~mA}$ & $\begin{array}{l}\text { (Plaza-Morlote et al., } \\
\text { 2017) }\end{array}$ \\
\hline $\begin{array}{l}\text { Marine sediment core } \\
\text { (glacial/interglacial sedimentation, } \\
\text { silt-clay) }\end{array}$ & $20 \mathrm{~s}$ & & \\
\hline
\end{tabular}

\subsubsection{Replicate measurements}

The accuracy and precision of element intensity records acquired by XRF scanning has been a subject of debate since the introduction of XRF core scanning devices (Croudace et al., 2006; Jansen et al., 1998). Calibration of element intensities with absolute concentrations obtained from reference samples is often used to prove the accuracy of XRF measurements but does not disclose information on the precision of these measurements. Moreover, the use of discrete reference samples for calibration reduces the non-destructive advantages of XRF scanning records and introduces additional uncertainties arising from differing sampling resolutions, sample inhomogeneities or sample preparation. However, replicate measurements can provide a non-destructive indication of the precision of XRF scanning records after log-ratio transformation (Weltje et al., 2015; Weltje and Tjallingii, 2008). If replicate measurements are provided, statistically robust confidence limits (90, 95 or $99 \%)$ are provided by the XELERATE software package (Weltje et al., 2015). Additionally, the software utilizes replicate measurements to assess the correlation significance provided by multivariate biplot analyses (Bloemsma, 2015). 
Standardized acquisition of replicate measurements (e.g. $i$ measurements every $n^{\text {th }}$ sample) is not facilitated by the Itrax acquisition software and need to be assigned manually. Ideally, the number of replicate measurements should be proportional (ca. 5-10\% of total data points) to the scanning resolution, the lithological variations, and the time available. Representative replicate measurements should cover both sedimentological extremes and average sediment compositions. Therefore, selecting two to three intervals (e.g. top, middle, bottom of the core section) for replicate analyses that cover lithological transitions or representative variations of the core lithology is most suitable.

Since XRF scanning can provide multi-elements data in a single scan, a simple method to quickly evaluate the credibility of each element is needed. One way to address this is to calculate the correlation coefficient of each elemental intensity between replicate measurements. Such information is useful to decide which element can be reproduced by the XRF scanning method. The relationship between correlation coefficient and average scanning intensity is also helpful in determining the signal-to-noise ratio of individual elements.

\subsubsection{Estimating signal-to-noise ratios to assess Itrax XRF data quality}

Estimating signal-to-noise ratios (SNRs) using the measured XRF spectra has at least two uses in Itrax XRF core scans. First, the quality of data that will be obtained at a site using different combinations of tube voltage, tube current and exposure time can be assessed using a series of test scans of a short section of core. Second, element profile suitability for interpretation of environmental change can be assessed after data acquisition.

The simple method for estimating SNRs developed by Ernst et al. (2014) for use in XRF analysis of glass fragments can be applied to Itrax XRF scan spectra. This method requires the definition of three ranges of channels within the XRF spectrum for each element, which can be based on the sum of spectra. These are the ranges of the XRF background on either side of the element peak and of the peak itself. Mean counts are calculated for each of the two background ranges, with the mean of these two values multiplied by the number of channels beneath the peak equal to the XRF background and the square root of this value representing the noise. The background is subtracted from the total counts in the channels within the element peak range to give the signal. A detailed explanation of the steps involved is given by Ernst et al. (2014).

These calculations can be performed rapidly on all spectra in a scanned core section using simple computer code. Apparently, negative SNRs can occur where the total counts in 
channels beneath the element peak are less than the mean background value multiplied by the width of the peak. The distribution of SNRs for an element within a scanned core section can be expressed using percentiles, allowing comparison of the limits of detection limits of quantification and between series of test scans.

As an example, distributions of SNRs for Rb and $\mathrm{Zr}$ obtained in series of scans using different combinations of tube voltage and current for test sections in floodplain cores from the River Boyne (Ireland), and River Severn (UK), are illustrated (Figure 11). The importance of these two elements is in their use in the $\mathrm{Zr} / \mathrm{Rb}$ log-ratio, a grain size proxy (Jones et al., 2012; Kylander et al., 2011). The graphs show that certain combinations of tube voltage and current produce substantial proportions of SNRs in the two test sections below the limit of quantification. The results suggest that either an alternative grain size proxy or a longer exposure time are needed for the River Boyne site, but that a tube voltage of at least $40 \mathrm{kV}$ will give acceptable results for the River Severn core. It should be noted that SNRs for Zr scanned at $40 \mathrm{kV}$ and $50 \mathrm{kV}$ may be substantially underestimated because of the position of the $\mathrm{Zr}$ peak adjacent to the Mo incoherent scatter peak, and the resulting curved background beneath it at higher tube voltages.

\section{Post-Analysis Considerations}

\subsection{Data visualization software}

The Itrax core scanner produces copious amounts of data. For example, scanning a 1-m sediment core on an Itrax at $200 \mu \mathrm{m}$ increments creates $5000 \mathrm{XRF}$-spectral data files. Graphical image files (optical.tif and radiograph. tif) and a results summary file (result.txt) are also created and saved. Efficient display of these data is essential to enable users to evaluate, analyze, interpret and present or publish the data.

RediCore: The Cox Analytical System RediCore program provides some useful visualization capability. It includes optical and radiographic image optimization and permits the plotting of up to two element profiles over optical and radiographic profiles along with correlation coefficients for the pair of variables selected.

ItraxPlot: There is a clear benefit in viewing multiple element profiles aligned to radiographic and optical images. ItraxPlot software (Raddec International, Southampton, UK) developed in 2003, allows rapid visualization of Itrax data (Croudace et al., 2006; Croudace and Rothwell, 2015a). The package was designed to be intuitive and easy to use and incorporates multiple features to effectively display the co-registered datasets of optical and radiographic images and elemental depth profiles (Figure 12). The program enables users to 
display, optimize, organize, adjust and analyse their data in just a few seconds. The final output selected by the user is suitable for presentations and publications. For maximum user flexibility and ability to display different elements, multiple copies of the Program can be open on a single computer. This approach allows researchers to rapidly inspect their core data and identify anomalies and data artefacts caused by cracked, damaged or sloping surfaces before interpretation. The ability to view a broad range of data at the same time helps users to evaluate variations in a number of core properties and to infer changes in mineralogy, heavy metal pollution signals, sediment accumulation rates, redox variations and much more.

Following evaluation, users can readily prepare high quality representations for use within scientific presentations or publications (Table 3).

Table 3 Summary of ItraxPlot features.

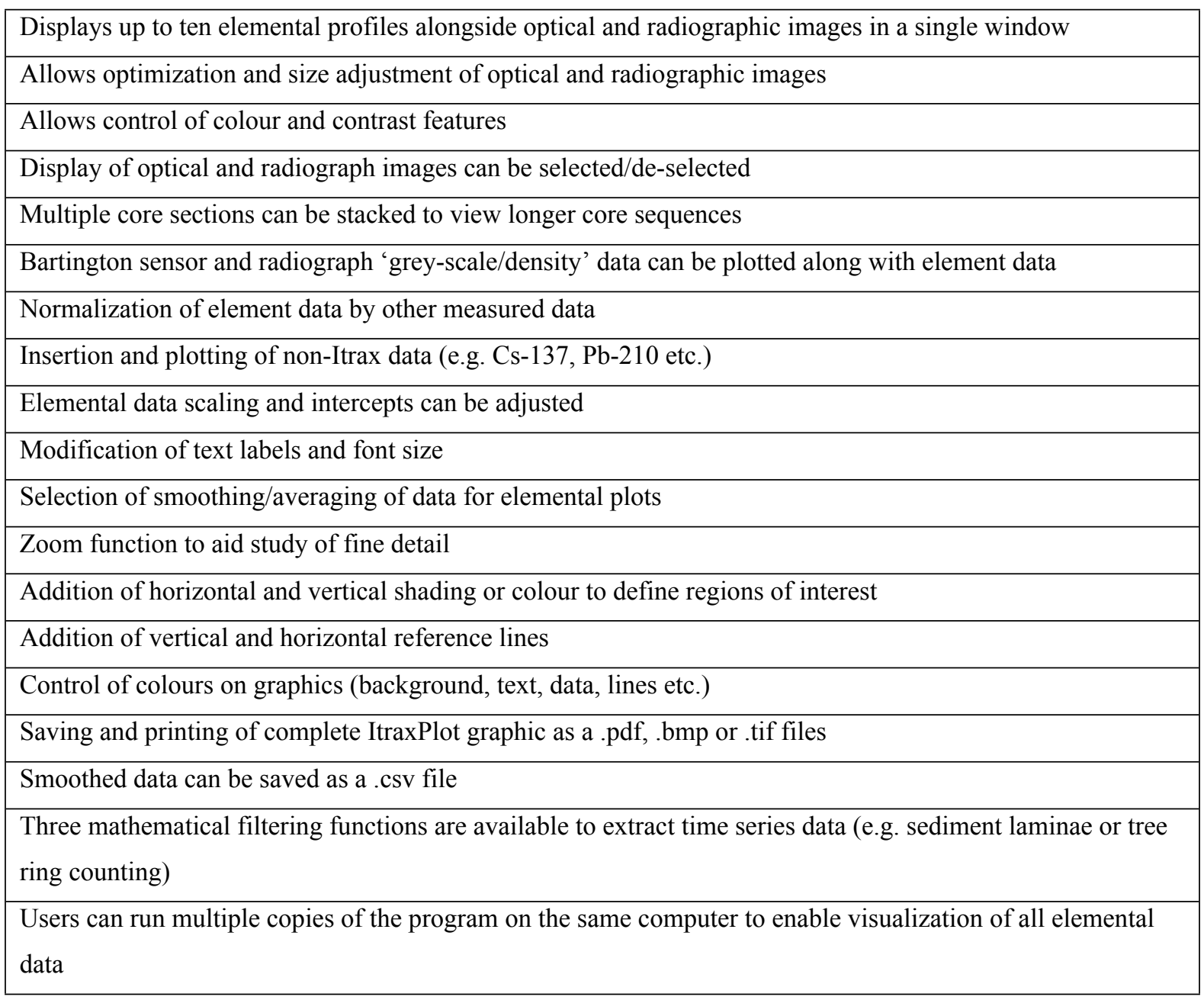

iPoint: The commercially developed iPoint suite (developed by Perigon Solutions Ltd) provides an alternative method for viewing and investigating Itrax XRF core scanner data. This program enables co-visualization of any type of numerical depth-referenced core data 
aligned to optical and radiographic images in one easy to navigate multi-scale display. For example, core logging instrumentation, discrete samples, CT scans or hand-drawn logs can all be included if required. Each dataset is depth referenced to allow easy initial interpretation of complex datasets. The iPoint suite is able to display an unlimited number of Itrax XRF core scanner elemental profiles with high-resolution images (Figure 13). Furthermore, the program has extensive features for assisting with micro-scale analysis, identification of correlation and marker horizons, as well as statistical analysis. A useful feature for an initial filter of poor quality data points in Itrax XRF core scanner data is the capability to flag and identify anomalies and artefacts in the data, specifically utilizing the validity, MSE, Ar and kcps data columns.

Xelerate: The Xelerate software offers calibration, plotting and visualization of XRF core scanner data (available at www.mennobloemsma.nl/software.php). This software package has been developed with the aim to integrate the different data types which are commonly acquired from hydrocarbon industry cores (e.g., permeability, porosity, lithofacies). The methods, however, are relevant to a much wider field of application than just hydrocarbon industry (Bloemsma, 2015). What sets this program apart is that all the tools and methods it contains acknowledge the fact that only log-ratios of element intensities have a unique relation with compositional variations in the sediment: a property that stems from the fact that every scanned data point can have a different measurement geometry (Weltje and Tjallingii, 2008). Around this central idea, several features have been developed as outlined below.

\section{Quantitative calibration}

Transformation of element intensities into element concentrations is one of the main features of Xelerate. The program features the bivariate calibration approach outlined by Weltje and Tjallingii (2008), as well as a state-of-the-art multivariate method based on Partial Least Squares Regression (Weltje et al., 2015).

\section{Automatic calibration sample selection}

The program selects optimal calibration sample positions, and is aimed at ensuring compositional coverage rather than spatial coverage: sample positions are selected by employing statistical clustering of log-ratio transformed element intensities.

\section{Core plotting tool}

Scan data and automatically selected sample positions can be shown alongside or on top of core images. Calibrated scan data can also be displayed, together with the reference composition of the standards used in the calibration process (Fig. 14). To facilitate quick 
navigation through the core, the core plotting tool has scrolling and zooming functionality.

Biplot tool

The ability to make biplots facilitates simultaneous inspection of the correlation among the logratio-transformed element intensities, and the variations along the core (for an example, see Martin-Puertas et al., 2017). Biplots can be constructed from both raw and calibrated element intensities.

More details about these methods can be found in Bloemsma (2015). Executables of the Matlab-based programs AvaaXelerate (for Avaatech data) and ItraXelerate (for Itrax data) are freely available on the internet (www.mennobloemsma.nl/software.php).

\section{Conclusions}

A number of innovative techniques, methods and tweaks have been developed at different Itrax XRF core scanning labs around the world to deal with problematic samples, and improve post processing of the data, thus increasing the utility and range of application of the various parameters produced by the core scanner.

- Special sample holders have been developed to allow the scanning of frozen sediment, powdered samples, and ion exchange resins used in forensic studies.

- Computer scripts have been developed to allow production of X-ray images more than three times the width achieved by single run scanning. An algorithm to up-sample the produced X-ray images to their maximum resolution has also been developed.

- By extensive testing, the minimum required exposure times have been established for a number of elements, allowing the required scanning time to be minimized for larger sample sets.

- Statistical methods have been developed to assess the reproducibility of the produced elemental data.

- ItraxPlot visualization software was developed to enable rapid inspection of Itrax elemental profiles correctly aligned with optical and radiographic images. The ability to study a broad range of co-registered profile data has made ItraxPlot an invaluable tool for Itrax laboratories.

- iPoint enables co-visualisation of any numerical depth-referenced core data types aligned to optical and radiographic images in an easy to navigate multi-scale display. 
- Xelerate facilitates analysis, calibration and visualization of element intensity data and core photographs. The key feature of Xelerate is that all of its methods and tools are based upon analysis of log-ratios of, rather than absolute element intensities.

Core scanning XRF is an invaluable tool for investigating the geomorphological, climatological, and contaminant history of environmental systems in marine, lacustrine and terrestrial settings. The aforementioned advancements expand the range of XRF Core Scanning to new settings initially assumed to be impossible when XRF core scanning was first developed two decades ago. However, further advancements are required to improve XRF core scanning, including better determination of accuracy and precision of various XRF core scanners, rigorous testing of various calibration methods in a variety of settings using multiple sample types, methodological adjustments to ensure accurate and precise measurement of sample material, and possible development of a more extensive selection of sediment standards for use in calibration.

\section{Acknowledgement}

Thanks to Carina Johansson for help with the ITRAX core scanning at the Department of Geological Science at Stockholm University. We also acknowledge the shipboard party of Leg 2 of the 2014 SWERUS-C3 Arctic Ocean Expedition for collecting Core SWERUS-L24-PC1, used for the radiographic imagery in this study. This manuscript represents National Resources Canada (NRCAN) contribution number 20180083. This work was financially supported by the "The Featured Areas Research Center Program within the framework of the Higher Education Sprout Project by the Ministry of Education (MOE) in Taiwan. LL acknowledges financial support from Ministry of Science and Technology (MOST grant 1062116-M-002 -021). 


\section{References}

Barrett, S., Starnberger, R., Tjallingii, R., Brauer, A., Spötl, C., 2017. The sedimentary history of the inner-alpine Inn Valley, Austria: extending the Baumkirchen type section further back in time with new drilling. Journal of Quaternary Science 32, 63-79.

Beck, K.K., Fletcher, M.-S., Gadd, P.S., Heijnis, H., Jacobsen, G.E., 2017. An early onset of ENSO influence in the extra-tropics of the southwest Pacific inferred from a 14, 600 year high resolution multi-proxy record from Paddy's Lake, northwest Tasmania. Quaternary Science Reviews 157, 164-175.

Bloemsma, M., 2015. Development of a modelling framework for core data integration using XRF scanning. Delft University of Technology, Delft, p. 217.

Buechi, M.W., Frank, S.M., Graf, H.R., Menzies, J., Anselmetti, F.S., 2017. Subglacial emplacement of tills and meltwater deposits at the base of overdeepened bedrock troughs. Sedimentology 64, 658-685.

Crann, C.A., Patterson, R.T., Macumber, A.L., Galloway, J.M., Roe, H.M., Blaauw, M., Swindles, G.T., Falck, H., 2015. Sediment accumulation rates in subarctic lakes: Insights into age-depth modeling from 22 dated lake records from the Northwest Territories, Canada. Quaternary Geochronology 27, 131-144.

Croudace, I.W., Rindby, A., Rothwell, R.G., 2006. ITRAX: description and evaluation of a new multi-function X-ray core scanner, in: Rothwell, R.G. (Ed.), New techniques in sediment core analysis. Geological Society of London, London, pp. 51-63.

Croudace, I.W., Rothwell, R.G., 2015a. ItraxPlot: An Intuitive flexible program for rapidly visualising Itrax data, in: Croudace, I.W., Rothwell, R.G. (Eds.), Micro-XRF Studies of Sediment Cores: Applications of a non-destructive tool for the environmental sciences. Springer Netherlands, Dordrecht, pp. 613-624.

Croudace, I.W., Rothwell, R.G., 2015b. Micro-XRF Studies of Sediment Cores, in: Smol, J.P. (Ed.), Developments in Paleoenvironmental Research. Springer, Dordrecht, p. 656.

Croudace, I.W., Thomson, J. and Rothwell, G., 2003. Initial evaluation of the ITRAX microXRF sediment core scanner, New Ways of Looking at Sediment Cores and Core Data: an international conference and workshop at Southampton Oceanography Centre. SOC, Southampton, p. 14.

Ernst, T., Berman, T., Buscaglia, J., Eckert-Lumsdon, T., Hanlon, C., Olsson, K., Palenik, C., Ryland, S., Trejos, T., Valadez, M., Almirall, J.R., 2014. Signal-to-noise ratios in forensic glass analysis by micro X-ray fluorescence spectrometry. X-Ray Spectrometry 43, 13-21.

Finné, M., Kylander, M., Boyd, M., Sundqvist, H.S., Löwemark, L., 2015. Can XRF scanning of speleothems be used as a non-destructive method to identify paleoflood events in caves? International Journal of Speleology 44, 17-23.

Francus, P., Kanamaru, K., Fortin, D., 2015. Standardization and Calibration of XRadiographs Acquired with the ITRAX Core Scanner, in: Rothwell, R.G., Croudace, I.W. (Eds.), Micro-XRF Studies of Sediment Cores. Springer, Dordrecht, pp. 491-505.

Galman, V., Rydberg, J., de-Luna, S.S., Bindler, R., Renberg, I., 2008. Carbon and nitrogen loss rates during aging of lake sediment: Changes over 27 years studied in varved lake sediment. Limnology and Oceanography 53, 1076-1082.

Gjerløw, E., Haflidason, H., Pedersen, R.B., 2016. Holocene explosive volcanism of the Jan Mayen (island) volcanic province, North-Atlantic. Journal of Volcanology and Geothermal Research 321, 31-43. 
Gregory, B.R.B., Patterson, R.T., Reinhardt, E.G., Galloway, J.M., this issue. The iBox-FC: a new containment vesserl for Itrax X-ray fluorescence core-scanning of freeze cores. Quaternary International.

Gregory, B.R.B., Reinhardt, E.G., Macumber, A.L., Nasser, N.A., Patterson, R.T., Kovacs, S.E., Galloway, J.M., 2017. Sequential sample reservoirs for Itrax-XRF analysis of discrete samples. Journal of Paleolimnology 57, 287-293.

Guyard, H., Chapron, E., St-Onge, G., Anselmetti, F.S., Arnaud, F., Magand, O., Francus, P., Mélières, M.-A., 2007. High-altitude varve records of abrupt environmental changes and mining activity over the last 4000 years in the Western French Alps (Lake Bramant, Grandes Rousses Massif). Quaternary Science Reviews 26, 2644-2660.

Haschke, M., 2006. The Eagle III BKA system, a novel sediment core X-ray fluorescence analyser with very high spatial resolution, in: Rothwell, R.G. (Ed.), New techniques in sediment core analysis. Geological Society of London, London, pp. 31-37.

Huang, J.-J., Löwemark, L., Chang, Q., Lin, T.-Y., Chen, H.-F., Song, S.-R., Wei, K.-Y., 2016. Choosing optimal exposure times for XRF core-scanning: Suggestions based on the analysis of geological reference materials. Geochemistry, Geophysics, Geosystems, 1558-1566.

Jakobsson, M., Pearce, C., Cronin, T.M., Backman, J., Anderson, L.G., Barrientos, N., Björk, G., Coxall, H., de Boer, A., Mayer, L.A., Mörth, C.M., Nilsson, J., Rattray, J.E., Stranne, C., Semiletov, I., O'Regan, M., 2017. Post-glacial flooding of the Bering Land Bridge dated to $11 \mathrm{cal}$ ka BP based on new geophysical and sediment records. Climate of the Past 13, 991-1005.

Jansen, J.H.F., Van der Gaast, S.J., Koster, B., Vaars, A.J., 1998. CORTEX, a shipboard XRF-scanner for element analyses in split sediment cores. Marine Geology 151, 143153.

Jones, A.F., Macklin, M.G., Brewer, P.A., 2012. A geochemical record of flooding on the upper River Severn, UK, during the last 3750years. Geomorphology 179, 89-105.

Kylander, M.E., Ampel, L., Wohlfarth, B., Veres, D., 2011. High-resolution X-ray fluorescence core scanning analysis of Les Echets (France) sedimentary sequence: new insights from chemical proxies. Journal of Quaternary Science 26, 109-117.

Lintern, A., Leahy, P.J., Heijnis, H., Zawadzki, A., Gadd, P., Jacobsen, G., Deletic, A., McCarthy, D.T., 2016. Identifying heavy metal levels in historical flood water deposits using sediment cores. Water Research 105, 34-46.

Löwemark, L., Chen, H.-F., Yang, T.-N., Kylander, M., Yu, E.-F., Hsu, Y.-W., Lee, T.-Q., Song, S.-R., Jarvis, S., 2011. Normalizing XRF-scanner data: A cautionary note on the interpretation of high-resolution records from organic-rich lakes. Journal of Asian Earth Sciences 40, 1250-1256.

Löwemark, L., Zheng, Y.-C., Das, S., Yeh, C.-P., Chen, T.-T., 2016. A peculiar reworking of Ophiomorpha shafts in the Miocene Nangang Formation, Taiwan. Geodinamica acta 28, 71-85.

Marshall, M., Schlolaut, G., Nakagawa, T., Lamb, H., Brauer, A., Staff, R., Ramsey, C.B., Tarasov, P., Gotanda, K., Haraguchi, T., Yokoyama, Y., Yonenobu, H., Tada, R., 2012. A novel approach to varve counting using $\mu \mathrm{XRF}$ and $\mathrm{X}$-radiography in combination with thin-section microscopy, applied to the Late Glacial chronology from Lake Suigetsu, Japan. Quaternary Geochronology 13, 70-80.

Martin-Puertas, C., Tjallingii, R., Bloemsma, M., Brauer, A., 2017. Varved sediment responses to early Holocene climate and environmental changes in Lake Meerfelder Maar (Germany) obtained from multivariate analyses of micro X-ray fluorescence core scanning data. Journal of Quaternary Science 32, 427-436. 
Ohlendorf, C., 2018. A sample carrier for measuring discrete powdered samples with an ITRAX XRF core scanner. X-Ray Spectrometry 47, 58-62.

Plaza-Morlote, M., Rey, D., Santos, J.F., Ribeiro, S., Heslop, D., Bernabeu, A., Mohamed, K.J., Rubio, B., Martíns, V., 2017. Southernmost evidence of large European Ice Sheetderived freshwater discharges during the Heinrich Stadials of the Last Glacial Period (Galician Interior Basin, Northwest Iberian Continental Margin). Earth and Planetary Science Letters 457, 213-226.

Profe, J., Neumann, L., Novothny, Á., Barta, G., Rolf, C., Frechen, M., Ohlendorf, C., Zolitschka, B., 2018a. Paleoenvironmental conditions and sedimentation dynamics in Central Europe inferred from geochemical data of the loess-paleosol sequence at Süttő (Hungary). Quaternary Science Reviews 196, 21-37.

Profe, J., Ohlendorf, C., 2018. X-ray fluorescence scanning of discrete samples - an economical perspective. Quaternary International, https://doi.org/10.1016/j.quaint.2018.1009.1022.

Profe, J., Wacha, L., Frechen, M., Ohlendorf, C., Zolitschka, B., 2018b. XRF scanning of discrete samples - a chemostratigraphic approach for loess-paleosol sequences exemplified on the Island of Susak, Croatia. Quaternary International.

Profe, J., Zolitschka, B., Schirmer, W., Frechen, M., Ohlendorf, C., 2016. Geochemistry unravels MIS 3/2 paleoenvironmental dynamics at the loess-paleosol sequence Schwalbenberg II, Germany. Palaeogeography, Palaeoclimatology, Palaeoecology 459, 537-551.

Renberg, I., 1982. Varved Lake-Sediments - Geochronological Records of the Holocene. Geologiska Föreningens i Stockholm Förhandlingar 104, 275-279.

Richter, T.O., van der Gaast, S., Koster, B., Vaars, A., Gieles, R., de Stigter, H.C., de Haas, H., van Weering, T.C.E., 2006. The Avaatech XRF core scanner: technical description and applications to NE Atlantic sediments, in: Rothwell, R.G. (Ed.), New techniques in sediment core analysis. Geological Society of London, London, pp. 39-50.

Rothwell, R.G., Croudace, I.W., 2015. Micro-XRF studies of sediment cores: A perspective on capability and application in the environmental sciences, in: Croudace, I.W., Rothwell, R.G. (Eds.), Micro-XRF Studies of Sediment Cores. Springer, Dordrecht, pp. $1-21$.

Rydberg, J., 2008. Assessing the stability of mercury and methylmercury in a varved lake sediment deposit. Environmental Science \& Technology 42, 4391-4396.

Shi, X., Yao, Z., Liu, Q., Larrasoaña, J.C., Bai, Y., Liu, Y., Liu, J., Cao, P., Li, X., Qiao, S., Wang, K., Fang, X., Xu, T., 2016. Sedimentary architecture of the Bohai Sea China over the last $1 \mathrm{Ma}$ and implications for sea-level changes. Earth and Planetary Science Letters 451, 10-21.

Skelton, A., Arghe, F., Pitcairn, I., 2010. Regional mapping of pre-metamorphic spilitization and associated chemical mobility in greenschist-facies metabasalts of the SW Scottish Highlands. Journal of the Geological Society 167, 1049-1061.

Thomson, J., Croudace, I.W., Rothwell, R.G., 2006. A geochemical application of the ITRAX scanner to a sediment core containing eastern Mediterranean sapropel units. Geological Society, London, Special Publications 267, 65-77.

Van Grieken, R., 1982. Preconcentration methods for the analysis of water by X-ray spectrometric techniques. Analytica Chimica Acta 143, 3-34.

Weltje, G.J., Bloemsma, M.R., Tjallingii, R., Heslop, D., Röhl, U., Croudace, I.W., 2015. Prediction of Geochemical Composition from XRF Core Scanner Data: A New Multivariate Approach Including Automatic Selection of Calibration Samples and Quantification of Uncertainties, in: Croudace, I.W., Rothwell, R.G. (Eds.), Micro-XRF 
Studies of Sediment Cores, Developments in Palaeoenvironmental Research. Springer, Berlin Heidelberg, pp. 507-534.

Weltje, G.J., Tjallingii, R., 2008. Calibration of XRF core scanners for quantitative geochemical logging of sediment cores: Theory and application. Earth and Planetary Science Letters 274, 423-438.

Zolitschka, B., Rolf, C., Bittmann, F., Binot, F., Frechen, M., Wonik, T., Froitzheim, N., Ohlendorf, C., 2014. Pleistocene climatic and environmental variations inferred from a terrestrial sediment record - the Rodderberg Volcanic Complex near Bonn, Germany. Zeitschrift der Deutschen Gesellschaft für Geowissenschaften 165, 407-424.

\section{Figure caption}

Figure 1. If the sample surface is poor due to gaps, cracks, holes from the removal of discrete samples or other disturbances, then a first image obtained is taken and saved (A), and the PTFE-tape is applied to cover the gaps above the bi-directional ultra-thin PET film (B, C). The surface scan is then performed again, after which the tape is removed and the XRF scan can be performed.

Figure 2. (A) Schematic illustration of a Russian Corer and the sampling (as seen from above) of sediment within a Russian Corer, resulting in a semi-cylindrical core. (B) The obtained core is often considerably smaller than the liner used for storage. If the protruding edges of the liner interfere with the safety guards, the measurements will fail. The core is flipped onto a board and the analysis is performed on the outer curved part of the core. (C) Scanning procedure for whole round Geo Cores. The extruded core is wrapped in cling-film, which is peeled back to expose the area at the top of the core that will be measured.

Figure 3. Detailed dimensions for the construction of the iBox-FC (reproduced from Gregory et al., this issue). (A) Cross sectional and Aerial views of the iBox-FC showing detailed dimensions of Styrofoam box and HDPE dividers. Note: not shown here are the $2 \mathrm{~mm}$ wide slots cut half way up the height of HDPE dividers at the intersection of long and wide HDPE pieces that allow the HDPE to be slotted together. (B) Image showing how the different components of the iBox-FC are slotted together. (C) The iBox-FC slotted into the rails of the Itrax-XRF-CS at McMaster University, Hamilton, ON, Canada. 
Figure 4. Results from scanning a freeze core slab recovered from Control Lake, Northwest Territories, Canada. These results are from the first section of core CON01-1FRF1 (top picture). The dashed lines correspond to the end of the core, the grey shaded area represents a small crack visible on the core image, and the hatched box represents edge effects observed in the last $\sim 5 \mathrm{~mm}$ of the core.

Figure 5. (a) An example of the freeze dried varve plug supported by foam and plastic during freeze drying. (b) When left and right hand scans of the freeze-dried cores were compared they were found to match well.

Figure 6. Schematic image and example of sample carrier capable of analysing sediment samples that require minimal pretreatment (modified from Gregory et al., 2017). (A) Dimensions of the sample carrier consisting of sequential sample reservoirs. (B) Image of the sample carrier before samples have been loaded. (C) The brass loading assistant in place on the sample carrier. (D)A fully loaded sample carrier in place on Itrax XRF Core Scanner tracks and ready for analysis.

Figure 7. Variations in Ca (orange) and Fe (blue) across the wall material in the wall of the trace fossil Ophiomorpha. Dotted yellow line marks the path of the detector over the sample. Ophiomorpha is believed to be a dwelling structure constructed by crustaceans. In order to stabilize the burrow, the producer constructs a lined wall made up of ovoid pellets. Diagenetic processes related to the decomposition of organic material in the pellets may lead to enrichment of certain elements, in this case Fe and Ca.

Figure 8. A composite image of a short section of sediment core made up of 3 overlapping scans with different offsets from the centre. Despite significant overlap between the individual scans, the image width is increased from $17.6 \mathrm{~mm}$ for a single scan to $37.6 \mathrm{~mm}$ for this triple scan. The mollusc specimen visible in the $-1 \mathrm{~cm}$ offset scan would not have been found if only the standard centre scan was done. Image produced from marine sediment core SWERUS-L2-4-PC1 (Jakobsson et al., 2017). 
Figure 9. A close-up of the same mollusc highlighted in Figure 8, visualized using two different approaches. Left panel: the original .tif image produced by the Itrax software with manually adjusted contrast and brightness. Right panel: the same image area, but produced from the raw file using the MATLAB script (Supplementary File 1) which performs a spline interpolation along the $x$-axis of the radiographic image. The pixel density in the right image compared to the left image is $10 x$ higher in both directions, but the actual resolution is only improved in the y-direction.

Figure 10. The lowest exposure time for each element.

Figure 11. Change in SNRs with tube voltage and current for $\mathrm{Rb}$ and $\mathrm{Zr}$ in XRF scans of test sections from Crewbane Marsh, River Boyne, (left column; CM C1 S1), and the Roundabout, River Severn (right column; RO C13 S2) performed at $500 \mu \mathrm{m}$ resolution and 30 seconds exposure time.

Figure 12. Example of output from the ItraxPlot program. The program allows aligning the optical and radiographic images with plots of up to 10 parameters or their ratios produced by the Itrax Core Scanner.

Figure 13. iPoint image showing the integration of ITRAX data with core photograph, radiograph and core log. The selected section highlights the variation of major elements across turbidite beds from sediment core CD166-19 (Madeira Abyssal Plain). Data headers details the average values for each dataset in addition to range of values. Additional data can be displayed within each column if required. MSE column (green) shows the variation in Mean Squared Error downcore, and the associated spikes across coarser grained horizons. Far right hand column displays a chosen ratio $(\mathrm{Ti} / \mathrm{K})$. Ratios can be custom created according to user preferences.

Figure 14. Graphs produced with Xelerate that illustrate the functionality of the core plotting tool: core photographs $(A)$ can be displayed side-by-side with selected log-ratio's of element intensities (in this case $\mathrm{Al} / \mathrm{Si}$ ) (B), or alongside a selected log-ratio of major-oxide 
abundances, as obtained by quantitative calibration (C). In B and C, a $99 \%$ confidence band is shown in grey. The width of this confidence band is derived automatically from replicate scans for the intensity data, and from the goodness-of-fit for the calibrated intensities, respectively. Automatically selected sample positions are indicated in red, whereas calibration sample positions are shown in blue. The displayed interval is a part (section 2-1 until 2-25) of a sedimentary rock core from Carboniferous, retrieved from wellsite E10-3 in the Dutch sector of the North Sea (see Bloemsma, 2015). 

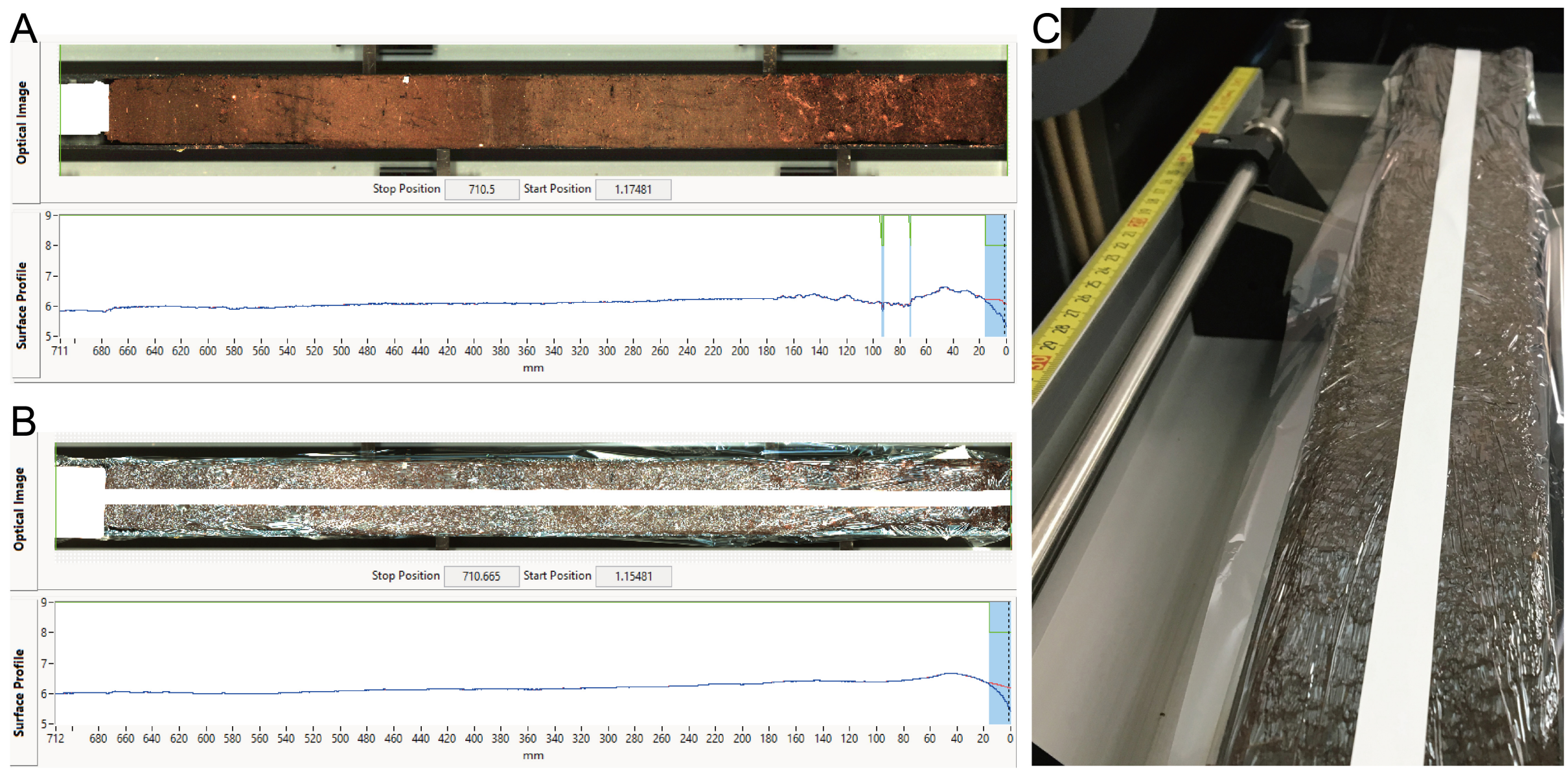


$$
\frac{T d u_{0} b}{b}
$$




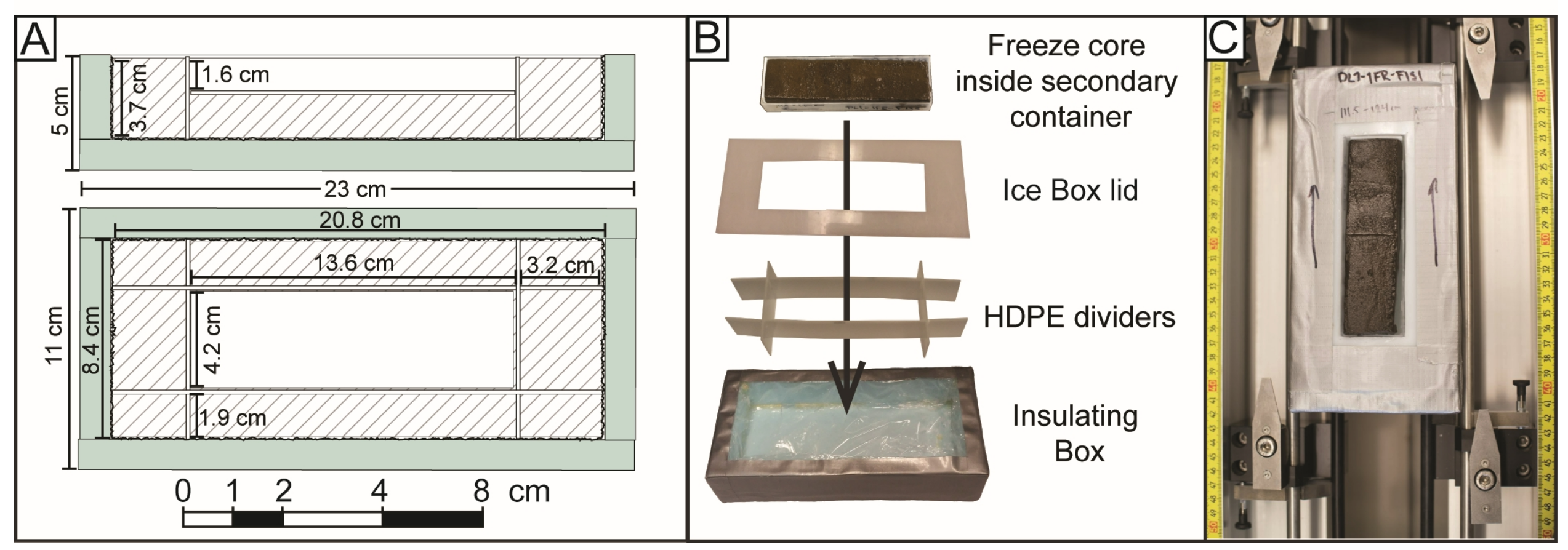




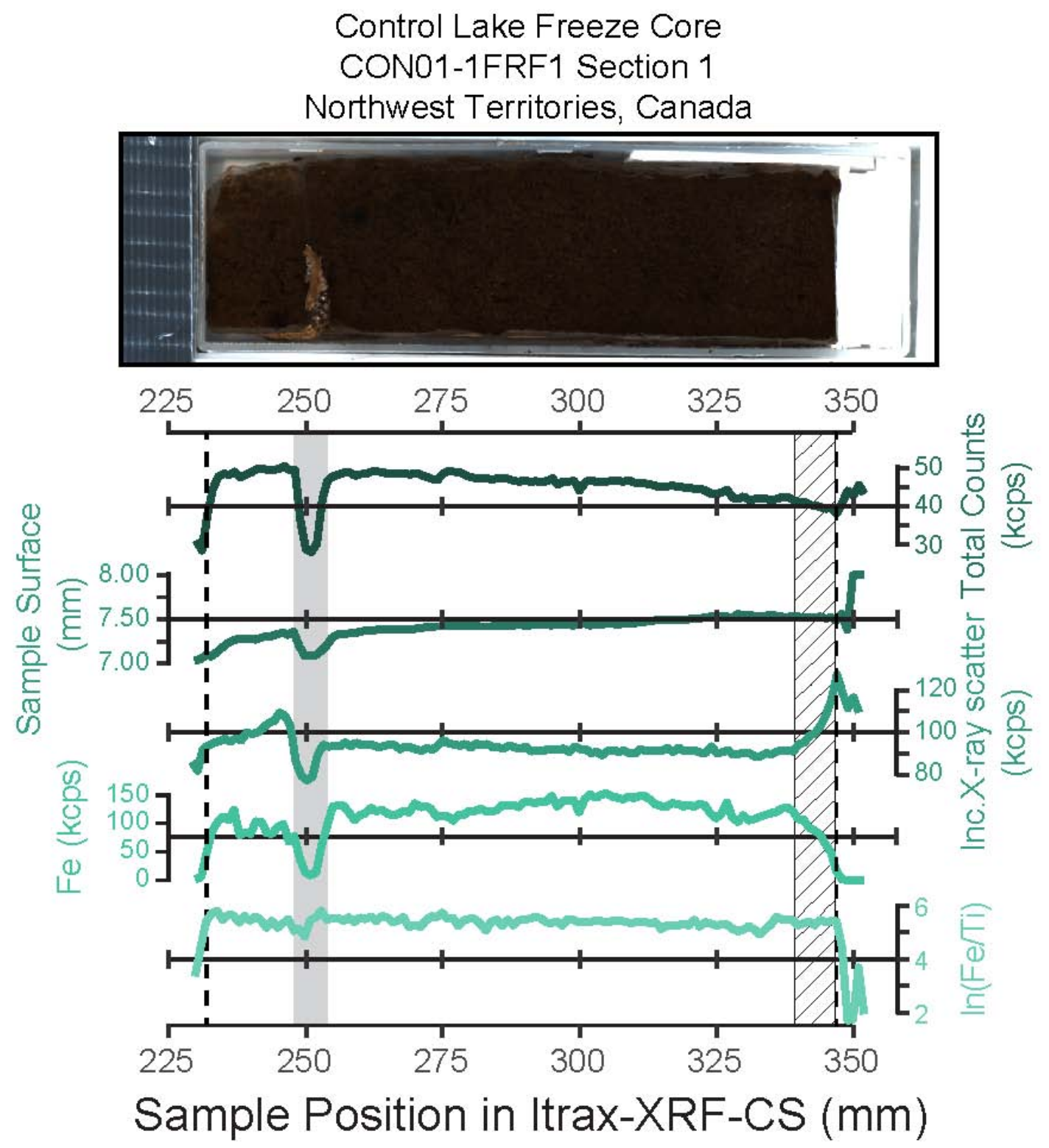


A

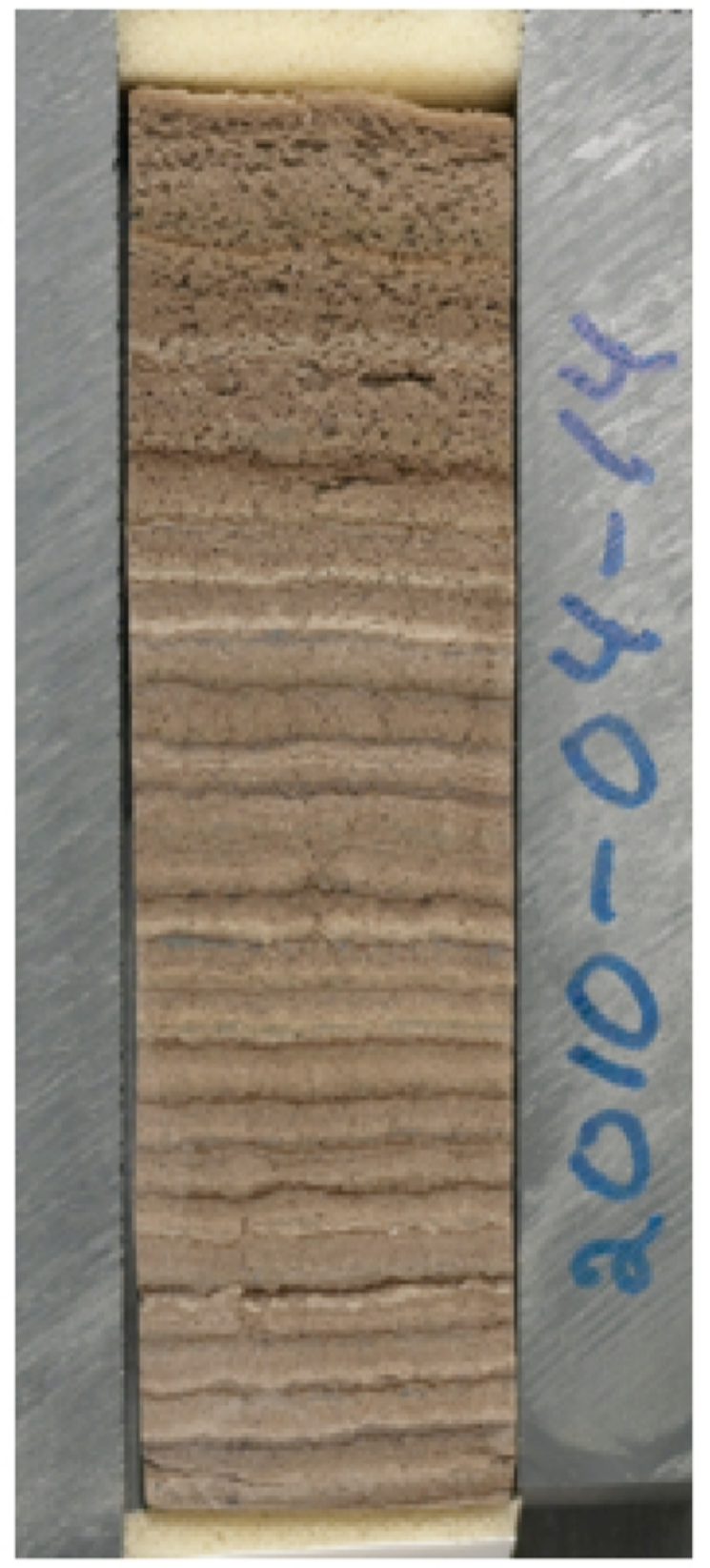

B

Fe (peak area)

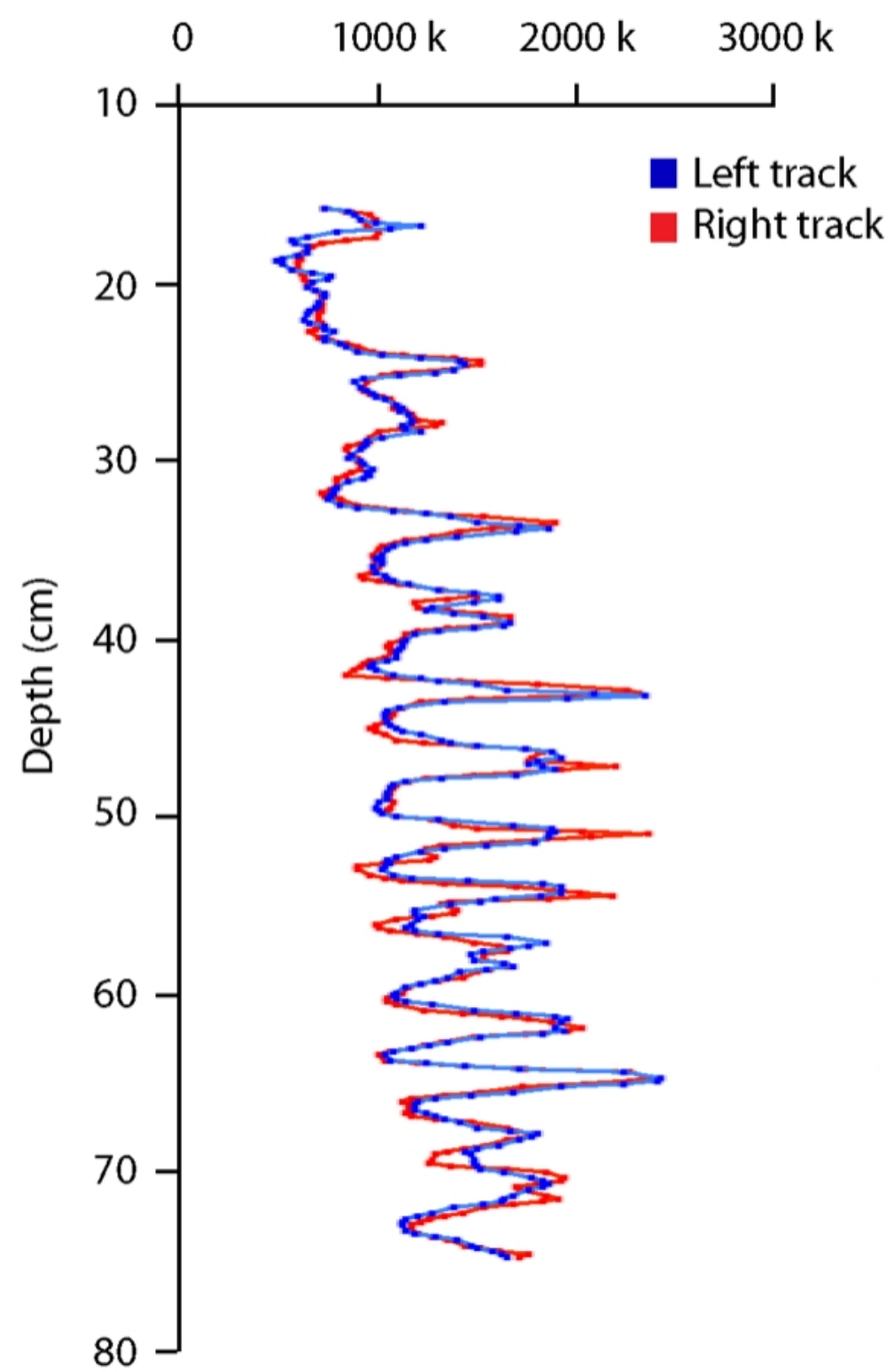




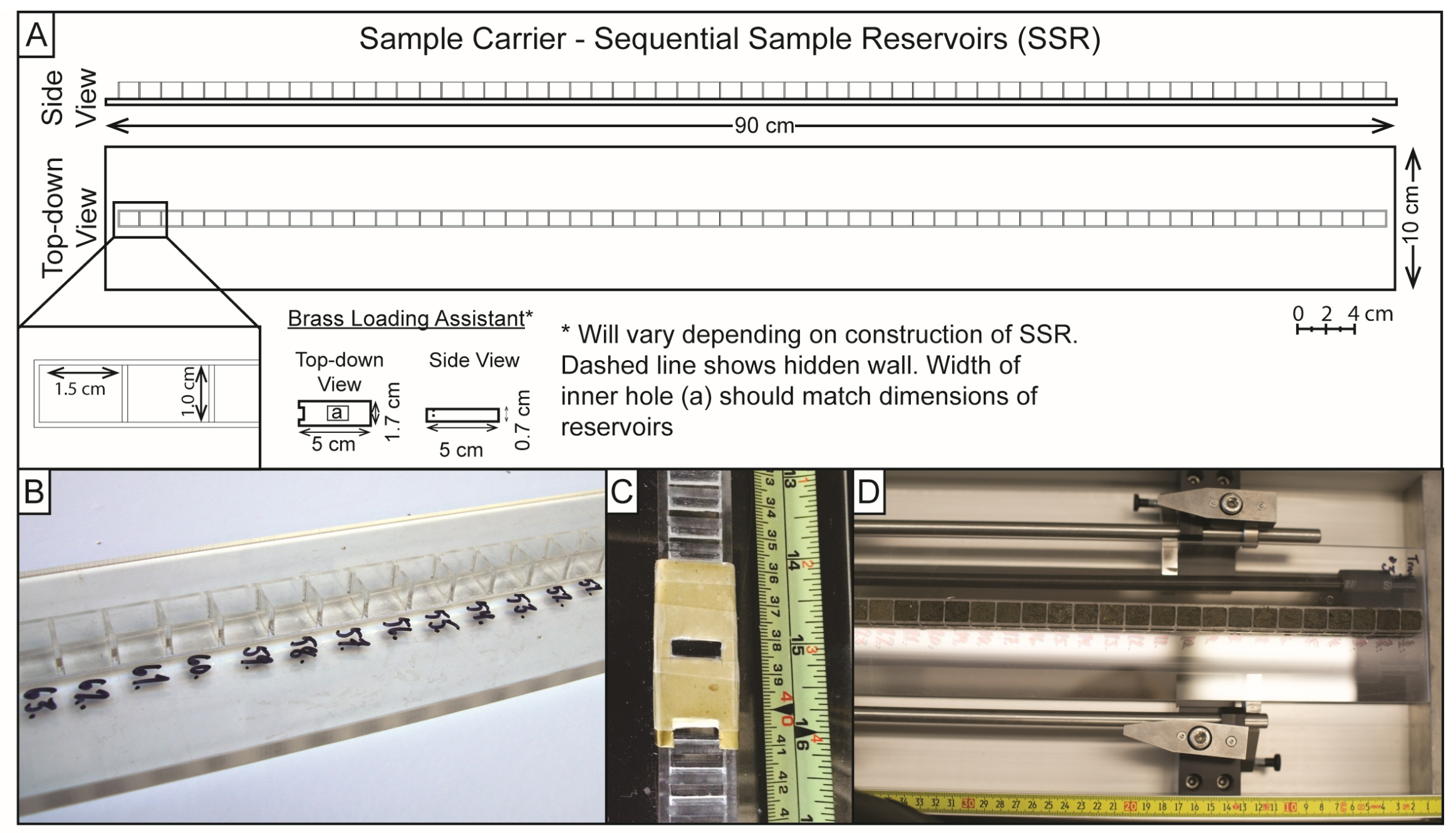




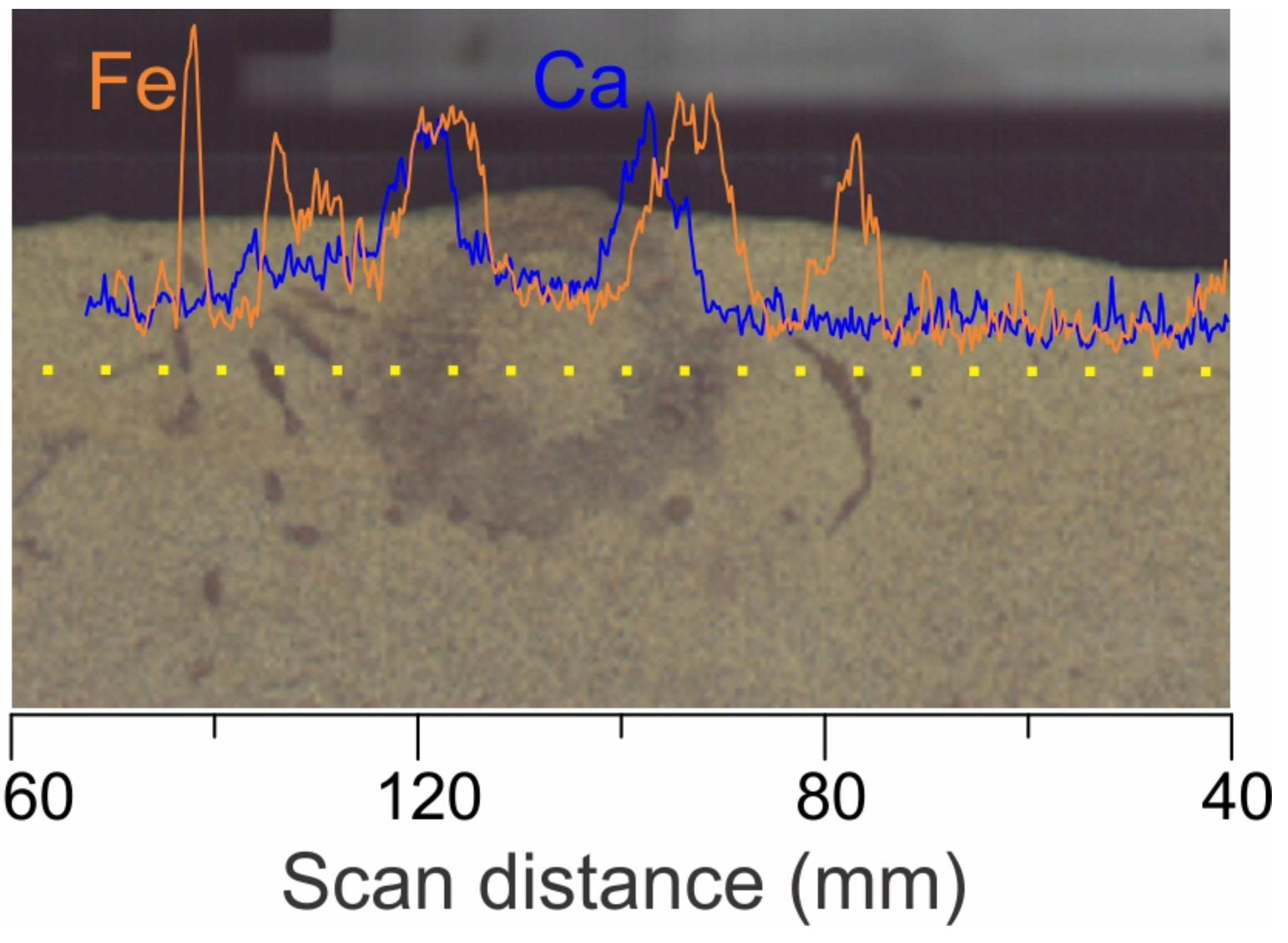




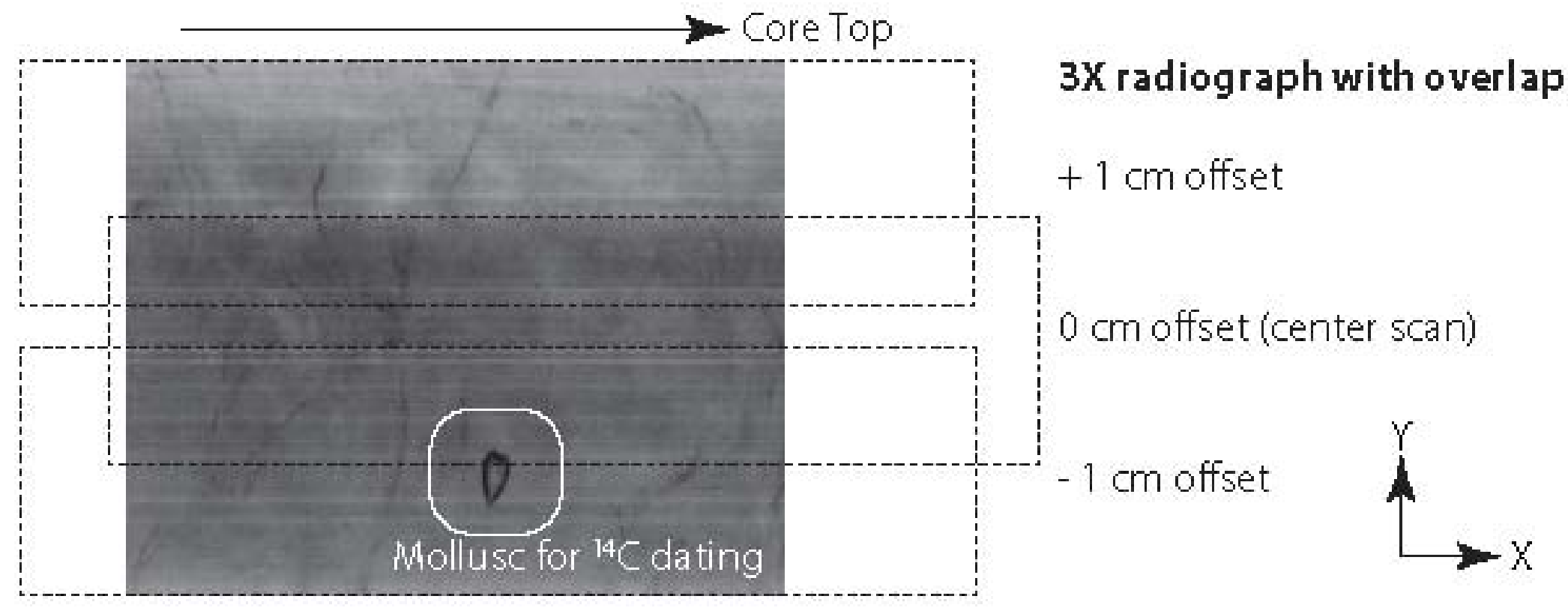



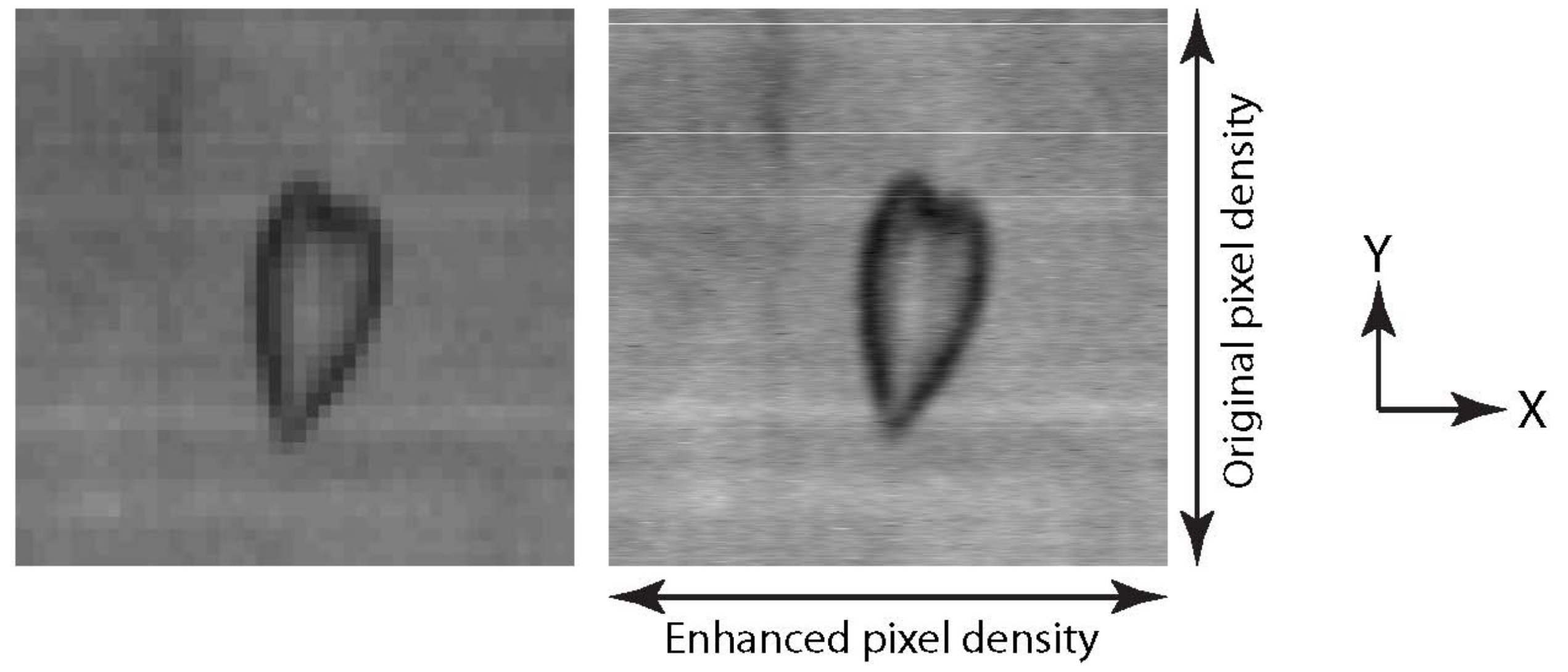


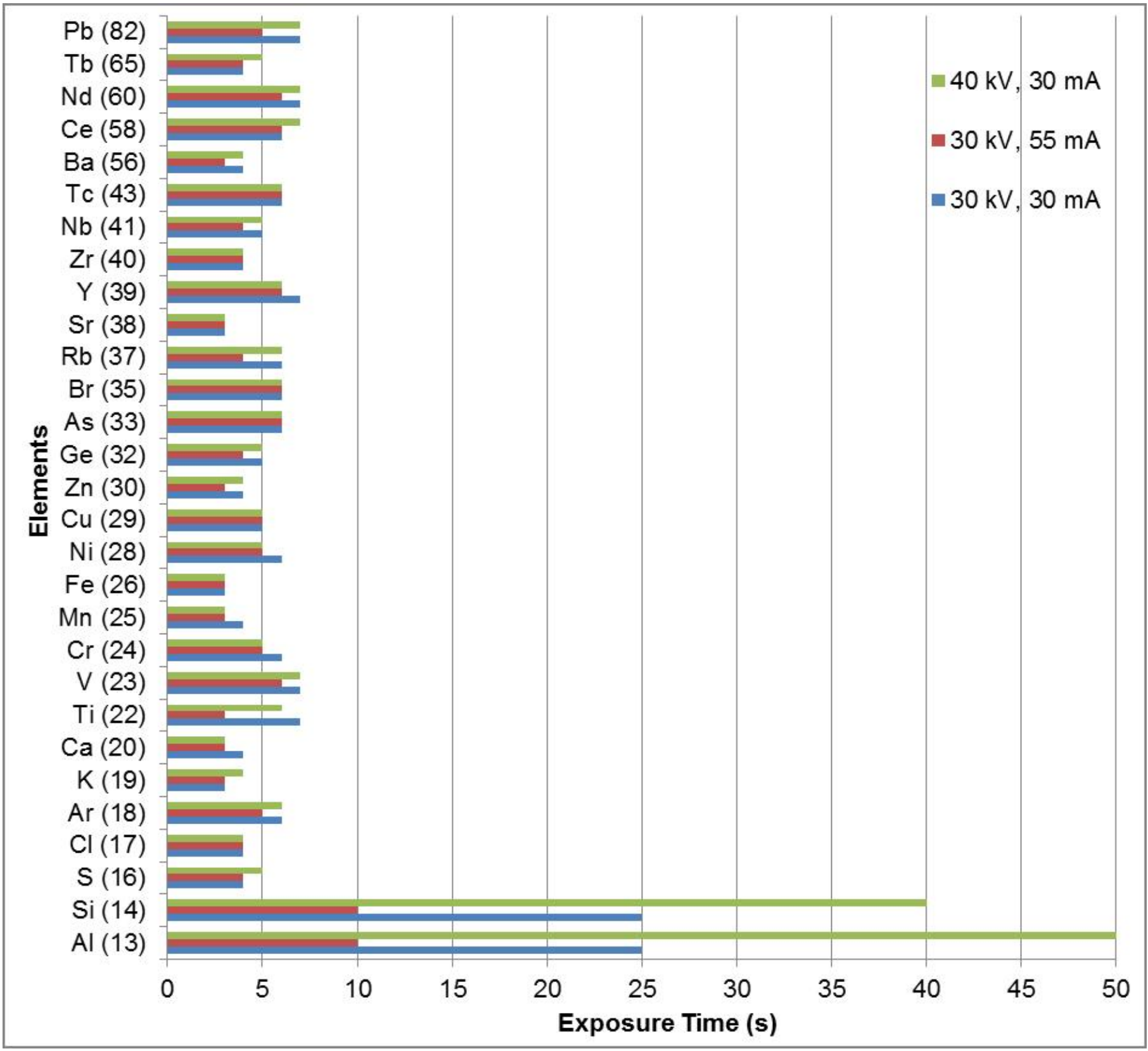




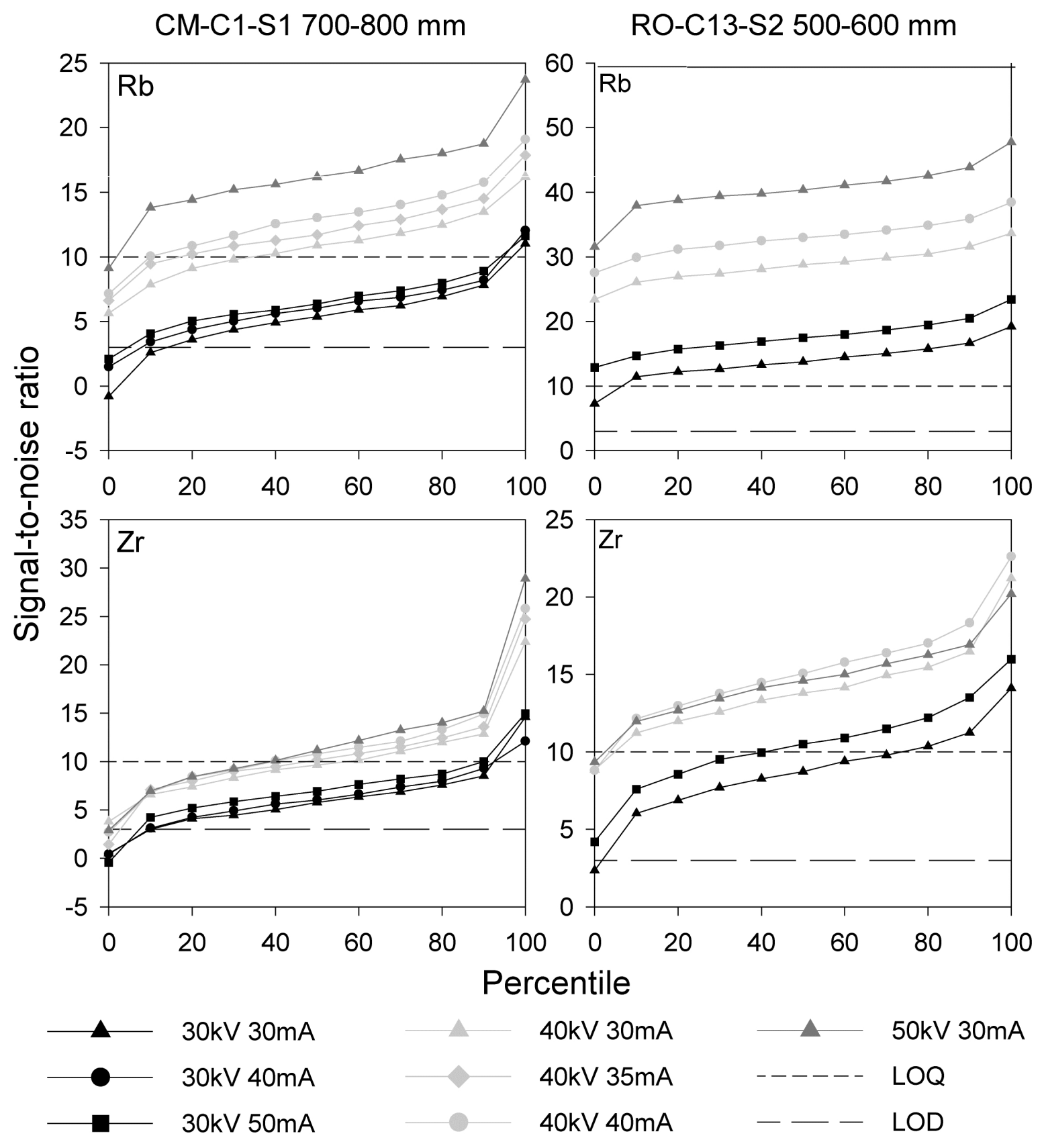




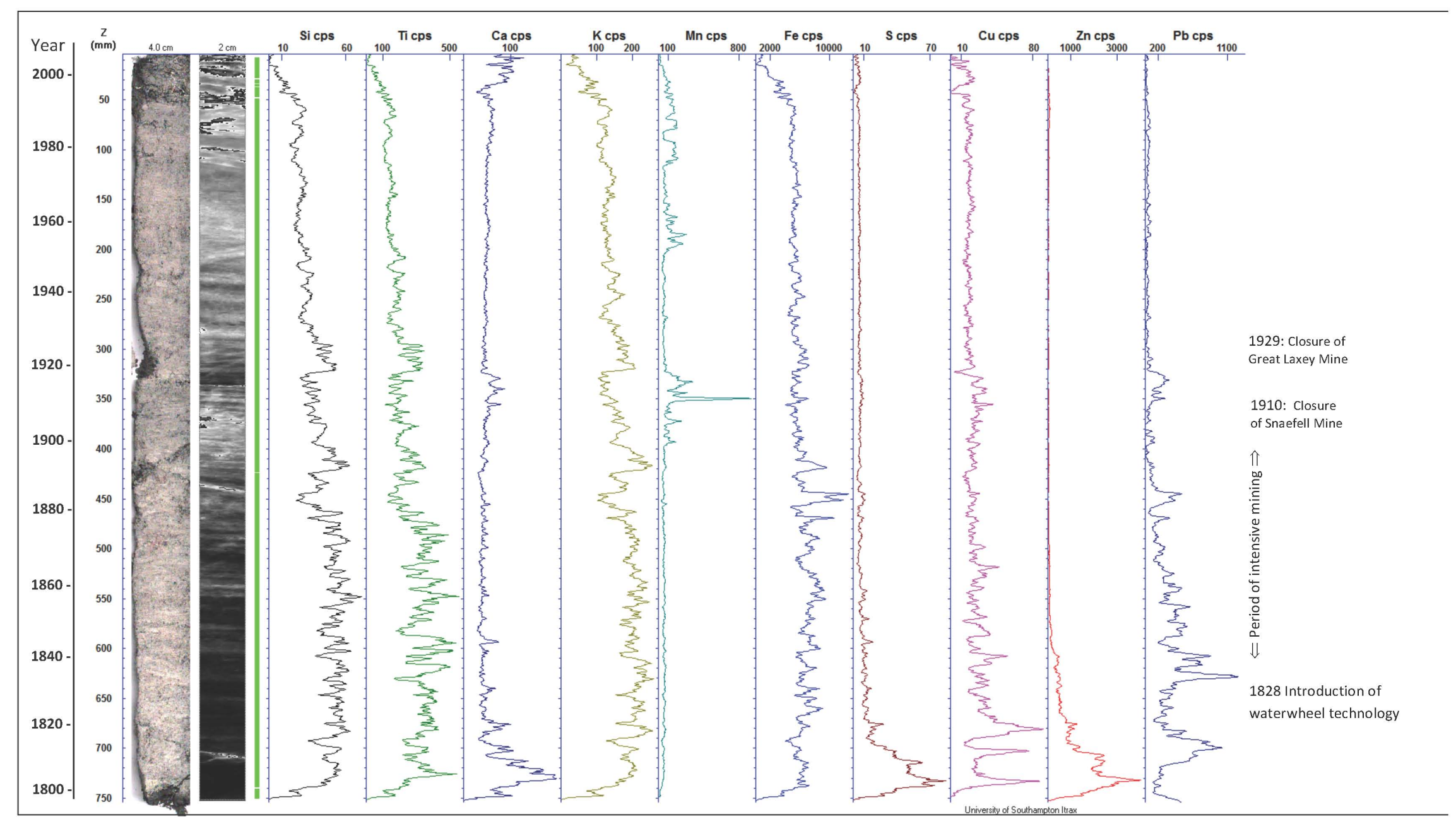



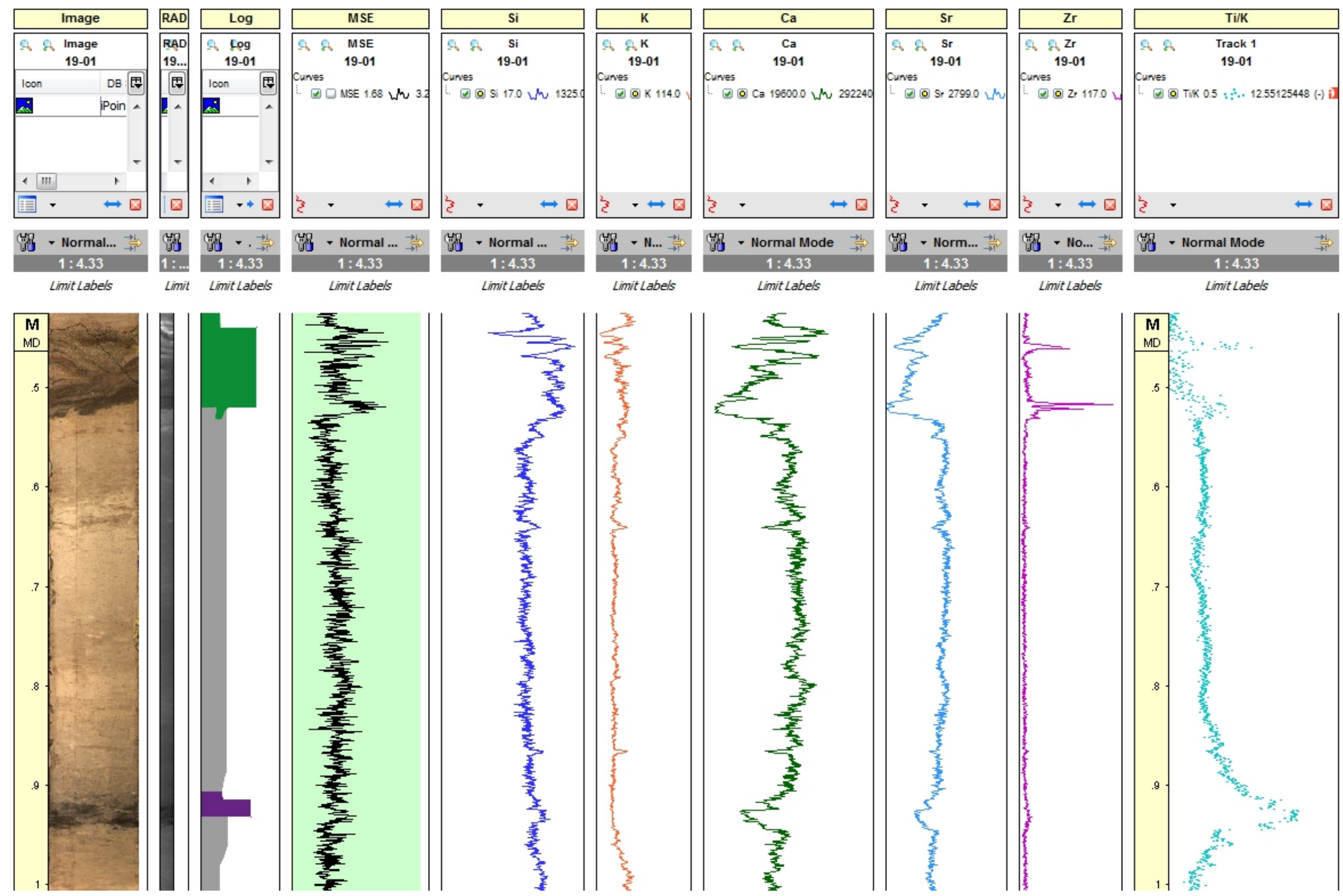
A)

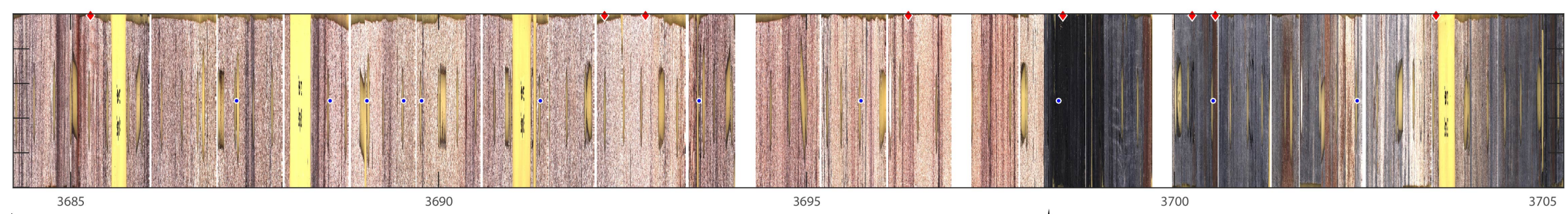

B)

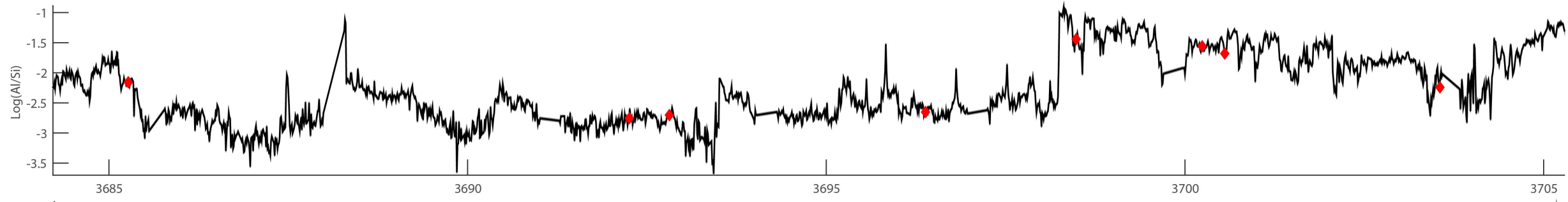

C)

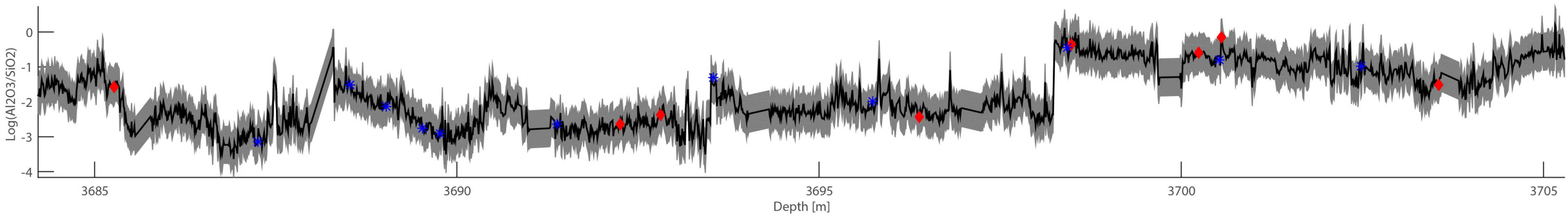

